\title{
Efficient Pd-Catalyzed Amination of Heteroaryl Halides
}

\author{
Mark D. Charles, Philip Schultz, Stephen L. Buchwald* \\ Department of Chemistry, Massachusetts Institute of Technology, Cambridge, MA 02139
}

\section{Supporting Information}

General Considerations: Tris(dibenzylideneacetone) dipalladium was purchased from Strem Chemical Company. Sodium tert-butoxide was purchased from Aldrich and stored in a glovebox, portions were removed and stored in a dessicator for up to 2 weeks. Lithium bis (trimethylsilylamide) solution in THF was purchased from Aldrich. $\mathrm{K}_{3} \mathrm{PO}_{4}$ (anhydrous) was purchased from Riedel-de Haen and was stored on the bench. Ligands 1, 2 and $\mathbf{4}$ were purchased from Strem Chemical Company. Unless otherwise stated all reagents were commercially available and used without further purification. Flash column chromatography was performed with EM science silica gel (230-400 mesh). Melting points were recorded on a Mel-Temp II, Laboratory Devices, Inc. Elemental analyses were performed by Atlantic Microlabs, Inc., Norcross, GA. IR spectra were recorded on an ASI ReactIR ${ }^{\mathrm{TM}} 1000$ and were obtained by placing the samples directly on the DiComp probe. ${ }^{1} \mathrm{H}$ and ${ }^{13} \mathrm{C}$ NMR were obtained on a Bruker Avance $400 \mathrm{MHz}$ instrument with chemical shifts reported relative to solvent $\left(7.26 \mathrm{ppm}\right.$ for residual $\left.\mathrm{CHCl}_{3}\right)$ or TMS as an internal standard.

General procedure 1. For the Pd-Catalyzed Amination of Pyrimidines, Thiophenes, Benzoxazoles and Benzothiazoles.

An oven dried schlenk tube containing a magnetic stirrer bar was evacuated and backfilled with argon. The tube was then charged with $\mathrm{Pd}_{2} \mathrm{dba}_{3}$, the appropriate ligand, base, aryl halide and amine in cases where these reagents were solids. The tube was evacuated and argon backfilled once and capped with a septa. The aryl halide and amine were added using a syringe in cases where these reagents were liquids followed by toluene. The tube was sealed under a positive pressure of argon with a teflon screw cap and placed into a pre-heated oil bath at the indicated temperature for the appropriate period of time. The tube was removed from the oil bath and allowed to cool to room temperature. Dodecane was added as an internal standard and the reaction mixture was analyzed by gas chromatography or thin layer chromatography. The contents of the tube were filtered through a pad of celite, washing with ethyl acetate until all of the product had eluted, as judged by thin layer chromatography. The organics were evaporated and purified by flash column chromatography to provide the products.

General procedure 2. For the Pd-Catalyzed Amination of Indoles

An oven dried schlenk tube containing a magnetic stirrer bar was evacuated and backfilled with argon. The tube was then charged with $\mathrm{Pd}_{2} \mathrm{dba}_{3}$, the appropriate ligand and aryl halide. The tube was evacuated, argon backfilled three times and capped with a septa. The amine was added using a syringe followed by a $1 \mathrm{M}$ solution of LiHMDS in THF. The tube was sealed under a positive pressure of argon with a teflon screw cap and 
placed into a pre-heated oil bath at $65^{\circ} \mathrm{C}$ for the appropriate period of time. The tube was removed from the oil bath and allowed to cool to room temperature. To the tube was added $1 \mathrm{M} \mathrm{HCl}(2 \mathrm{~mL})$, the contents of the tube were stirred for 5 minutes and then poured into a separatory funnel containing a saturated aqueous sodium bicarbonate solution $(20 \mathrm{~mL})$. The organics were extracted with ethyl acetate $(3 \times 20 \mathrm{~mL})$, washed with brine $(40 \mathrm{~mL})$, dried over magnesium sulfate and filtered. Dodecane was added as an internal standard and the reaction mixture was analyzed by gas chromatography or thin layer chromatography. The organics were evaporated under reduced pressure and the residue was purified by flash column chromatography.

2-(1-Phenyl-ethyl)-thiophene (Table 1, Entry 1). Following general procedure 1, a mixture of 2-chlorothiophene $(0.118 \mathrm{~g}, 0.092 \mathrm{~mL}, 1.00 \mathrm{mmol}), N$-methylaniline $(0.128 \mathrm{~g}$, $0.130 \mathrm{~mL}, 1.20 \mathrm{mmol})$, sodium tert-butoxide $(0.134 \mathrm{~g}, 1.40 \mathrm{mmol}), 2$ (16.4 mg, 0.04 mmol, $4 \mathrm{~mol} \%), \mathrm{Pd}(\mathrm{OAc})_{2}(4.4 \mathrm{mg}, 0.02 \mathrm{mmol}, 2 \mathrm{~mol} \%)$ and toluene (2 mL) was stirred at $85{ }^{\circ} \mathrm{C}$ for $19 \mathrm{~h}$. The crude reaction mixture was purified by flash column chromatography using 1:20 ethyl acetate:hexane, to yield the title compound as a yellow oil $(0.155 \mathrm{~g}, 82 \%)$. ${ }^{1} \mathrm{H}$ NMR (400 $\left.\mathrm{MHz} \mathrm{CDCl}_{3}\right)$ : $\delta$ 7.31-7.27 (m, 2H), 7.00-6.98 (m, 3H), 6.94-6.90 (m, 2H), $6.92(\mathrm{dd}, J=3.6 \mathrm{~Hz}, 1.3 \mathrm{~Hz}, 1 \mathrm{H}), 3.37(\mathrm{~s}, 3 \mathrm{H}) .{ }^{13} \mathrm{C}$ NMR $(100 \mathrm{MHz}$ $\mathrm{CDCl}_{3}$ ): $\delta 153.7,149.4,129.1,125.9,120.0,119.7,118.9,116.4,42.1$. IR (thin film cm${ }^{-1}$ ) 3105, 3091, 2944, 2879, 2811, 1598, 1542, 1495, 1474, 1441, 1420, 1318, 1297, 1245, 1200, 1111, 1059, 1017. Anal. Calcd for $\mathrm{C}_{11} \mathrm{H}_{11} \mathrm{NS}$ : C, 69.80. H, 5.86. Found C, 69.65. H, 5.73 .

Methyl-phenyl-thiophen-3-yl-amine (Table 1, Entry 2). ${ }^{1}$ Following general procedure 1 , a mixture of 3-chlorothiophene $(0.118 \mathrm{~g}, 0.092 \mathrm{~mL}, 1.00 \mathrm{mmol}), N$-methylaniline $(0.128 \mathrm{~g}, 0.130 \mathrm{~mL}, 1.20 \mathrm{mmol})$, sodium tert-butoxide $(0.134 \mathrm{~g}, 1.40 \mathrm{mmol}), 3(9.3 \mathrm{mg}$, $0.02 \mathrm{mmol}, 2 \mathrm{~mol} \%), \mathrm{Pd}_{2} \mathrm{dba}_{3}(4.5 \mathrm{mg}, 0.005 \mathrm{mmol}, 0.5 \mathrm{~mol} \%)$ and toluene $(2 \mathrm{~mL})$ was stirred at $100{ }^{\circ} \mathrm{C}$ for $17 \mathrm{~h}$. The crude reaction mixture was purified by flash column chromatography using 1:20 ethyl acetate:hexane, to yield the title compound as a light

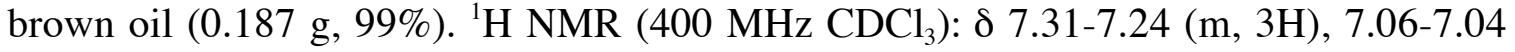
$(\mathrm{m}, 2 \mathrm{H}), 6.97-6.94(\mathrm{~m}, 1 \mathrm{H}), 6.92(\mathrm{dd}, J=5.2 \mathrm{~Hz}, 1.4 \mathrm{~Hz}, 1 \mathrm{H}), 6.61(\mathrm{dd}, J=3.1 \mathrm{~Hz}, 1.4$ $\mathrm{Hz}, 1 \mathrm{H}), 3.34$ (s, 3H). ${ }^{13} \mathrm{C}$ NMR $\left(100 \mathrm{MHz} \mathrm{CDCl}_{3}\right): \delta 149.4,148.5,129.2,125.1,123.4$, 120.9, 118.9, 107.9, 41.2. IR (thin film cm c $^{-1}$ 3107, 3089, 3037, 3027, 2933, 2879, 1598, 1536, 1493, 1387, 1318, 1189, 1127, 1088, 1063, 1028, 941, 874, 746. Anal. Calcd for $\mathrm{C}_{11} \mathrm{H}_{11} \mathrm{NS}: \mathrm{C}, 69.80 . \mathrm{H}, 5.86$.

4-Thiophen-3-yl-morpholine (Table 1, Entry 3). Following general procedure 1, a mixture of 3-chlorothiophene $(0.118 \mathrm{~g}, 0.092 \mathrm{~mL}, 1.00 \mathrm{mmol})$, morpholine $(0.104 \mathrm{~g}$, $0.105 \mathrm{~mL}, 1.20 \mathrm{mmol})$, sodium tert-butoxide (0.134 g, $1.40 \mathrm{mmol}), 2$ (16.4 mg, 0.04 mmol, $4 \mathrm{~mol} \%), \mathrm{Pd}_{2} \mathrm{dba}_{3}(9.1 \mathrm{mg}, 0.01 \mathrm{mmol}, 1 \mathrm{~mol} \%)$ and toluene $(2 \mathrm{~mL})$ was stirred at $100{ }^{\circ} \mathrm{C}$ for $24 \mathrm{~h}$. The crude reaction mixture was purified by flash column chromatography using 1:4 ethyl acetate:hexane, to yield the title compound as a white solid (0.134 g, 79\%), mp 86-88 ${ }^{\circ} \mathrm{C} .{ }^{1} \mathrm{H}$ NMR (400 $\left.\mathrm{MHz} \mathrm{CDCl}_{3}\right): \delta 7.28$ (dd, $J=5.2 \mathrm{~Hz}$, $3.1 \mathrm{~Hz}, 1 \mathrm{H}), 6.88(\mathrm{dd}, J=5.2 \mathrm{~Hz}, 1.5 \mathrm{~Hz}, 1 \mathrm{H}), 6.22(\mathrm{dd}, J=3.0 \mathrm{~Hz}, 1.5 \mathrm{~Hz}, 1 \mathrm{H}), 3.87$ (t, $J=4.8 \mathrm{~Hz}, 4 \mathrm{H}), 3.11(\mathrm{t}, J=4.8 \mathrm{~Hz}, 4 \mathrm{H}) .{ }^{13} \mathrm{C} \mathrm{NMR}\left(100 \mathrm{MHz} \mathrm{CDCl}_{3}\right): \delta 152.6,125.8$, 119.8, 100.6, 66.8, 50.9. IR (thin film cm $\mathrm{cm}^{-1}$ ) 2964, 2856, 2833, 1544, 1457, 1268, 1233, 
1189, 1162, 1111, 1081, 1065, 962, 924, 872, 771. Anal. Calcd for $\mathrm{C}_{8} \mathrm{H}_{11} \mathrm{NOS}$ : C, 56.77 . H, 6.55. Found C, 56.89. H, 6.55.

Phenyl-thiophen-3-yl-amine (Table 1, Entry 4). ${ }^{1}$ Following general procedure 1, a mixture of 3-bromothiophene $(0.163 \mathrm{~g}, 0.093 \mathrm{~mL}, 1.00 \mathrm{mmol})$, aniline $(0.111 \mathrm{~g}, 0.109$ $\mathrm{mL}, 1.20 \mathrm{mmol})$, sodium tert-butoxide $(0.134 \mathrm{~g}, 1.40 \mathrm{mmol}), 3(37.3 \mathrm{mg}, 0.08 \mathrm{mmol}, 8$ mol\%), $\mathrm{Pd}_{2} \mathrm{dba}_{3}(18.3 \mathrm{mg}, 0.02 \mathrm{mmol}, 2 \mathrm{~mol} \%)$ and toluene $(2 \mathrm{~mL})$ was stirred at $85{ }^{\circ} \mathrm{C}$ for $14 \mathrm{~h}$. The crude reaction mixture was purified by flash column chromatography using 1:9 ethyl acetate:hexane, to yield the title compound as a brown solid $(0.138 \mathrm{~g}, 79 \%), \mathrm{mp}$ 43-44 ${ }^{\circ} \mathrm{C} .{ }^{1} \mathrm{H}$ NMR (400 $\left.\mathrm{MHz} \mathrm{CDCl}_{3}\right)$ : $\delta$ 7.30-7.25 (m, 3H), $7.01(\mathrm{~m}, 1 \mathrm{H}), 6.99(\mathrm{~m}, 1 \mathrm{H})$, $6.94(\mathrm{dd}, J=5.1 \mathrm{~Hz}, 1.4 \mathrm{~Hz}, 1 \mathrm{H}), 6.90(\mathrm{~m}, 1 \mathrm{H}), 6.76(\mathrm{dd}, J=3.0 \mathrm{~Hz}, 1.4 \mathrm{~Hz}, 1 \mathrm{H}), 5.73$ (s, br, 1H). ${ }^{13} \mathrm{C}$ NMR (100 $\left.\mathrm{MHz} \mathrm{CDCl}_{3}\right): \delta 144.7,141.6,129.5,125.3,123.0,120.0$, 115.7, 106.6. IR (thin film cm ${ }^{-1}$ ) 3394, 1600, 1555, 1532, 1497, 1445, 1430, 1314, 1252, 1171, 744. Anal. Calcd for $\mathrm{C}_{10} \mathrm{H}_{9} \mathrm{NS}$ : C, 68.53. H, 5.18.

4-Benzo[b]thiophen-3-yl-phenyl-amine (Table 1, Entry 5). Following general procedure 1, a mixture of 3-bromothianaphthene $(0.213 \mathrm{~g}, 0.130 \mathrm{~mL}, 1.00 \mathrm{mmol})$, aniline $(0.111 \mathrm{~g}, 0.109 \mathrm{~mL}, 1.20 \mathrm{mmol})$, sodium tert-butoxide $(0.134 \mathrm{~g}, 1.40 \mathrm{mmol}), 1$ (38.0 mg, $0.08 \mathrm{mmol}, 8 \mathrm{~mol} \%), \mathrm{Pd}_{2} \mathrm{dba}_{3}(18.2 \mathrm{mg}, 0.02 \mathrm{mmol}, 2 \mathrm{~mol} \%)$ and toluene $(2 \mathrm{~mL})$ was stirred at $100{ }^{\circ} \mathrm{C}$ for $18 \mathrm{~h}$. The crude reaction mixture was purified by flash column chromatography using 1:9 ethyl acetate:hexane to yield the title compound as a dark red solid $(0.185 \mathrm{~g}, 82 \%), \mathrm{mp} 79-80{ }^{\circ} \mathrm{C} .{ }^{1} \mathrm{H}$ NMR (400 $\left.\mathrm{MHz} \mathrm{CDCl}_{3}\right)$ : $\delta$ 7.87-7.85 (m, $\left.1 \mathrm{H}\right)$, 7.69-7.67 (m, 1H), 7.41-7.39 (m, 2H), 7.30-7.26 (m, 2H), 7.04-7.01 (m, 3H), $6.92(\mathrm{t}, J=$ $7.3 \mathrm{~Hz}, 1 \mathrm{H}), 5.78$ (s, br, $1 \mathrm{H}) .{ }^{13} \mathrm{C}$ NMR $\left(100 \mathrm{MHz} \mathrm{CDCl}_{3}\right): \delta 144.8,139.0,135.9,134.7$, 129.5, 125.0, 124.1, 123.4, 120.7, 120.3, 116.2, 109.2. IR (thin film $\mathrm{cm}^{-1}$ ) 3390, 1602, $1573,1526,1511,1495,1432,1343,1245,750,719$. Anal. Calcd for $\mathrm{C}_{14} \mathrm{H}_{11} \mathrm{NS}$ : C, 74.63. $\mathrm{H}, 4.92$. 

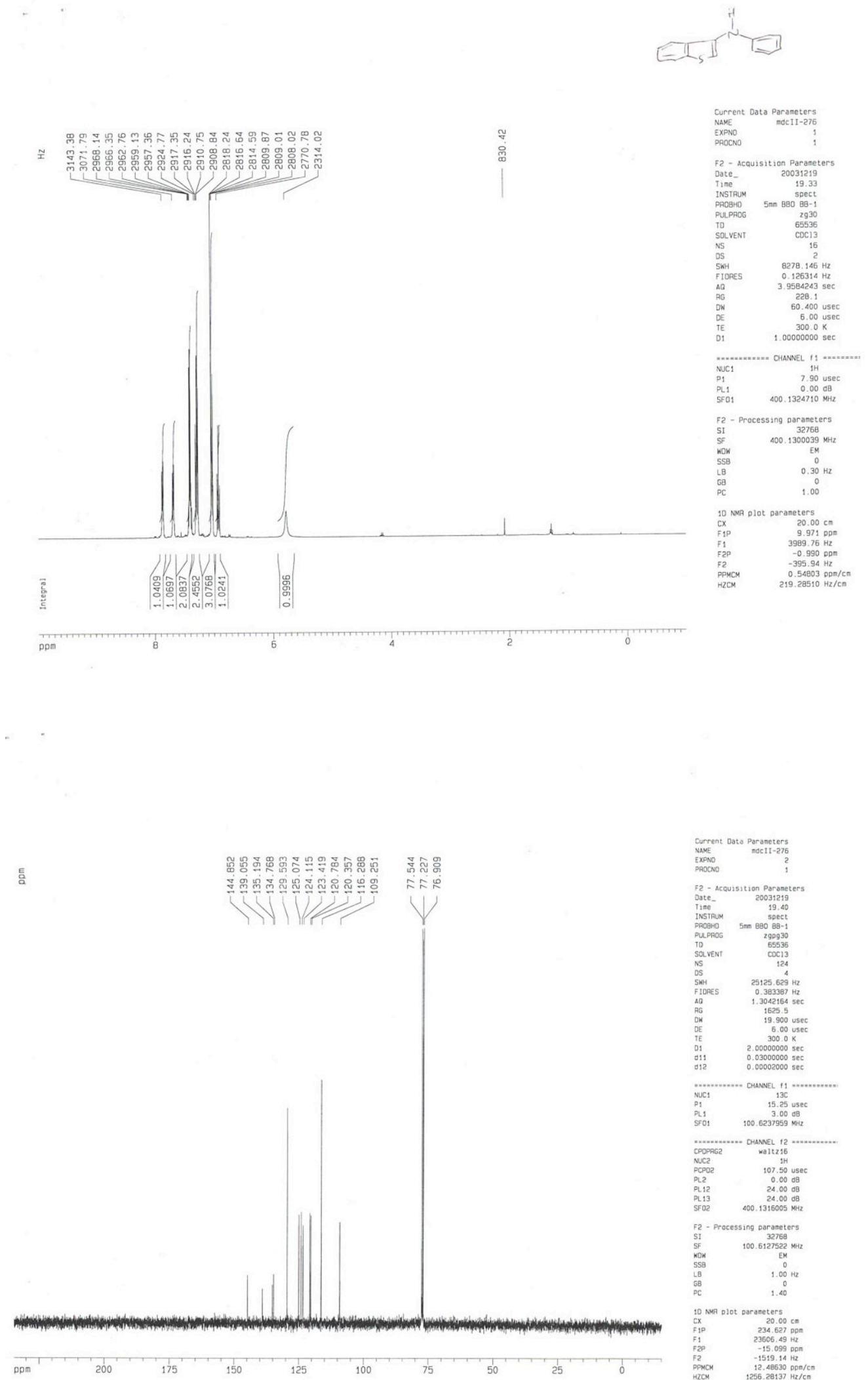

ppm 
4-Benzo $[b]$ thiophen-3-yl-morpholine (Table 1, Entry 6). Following general procedure 1 , a mixture of 3-bromothianaphthene $(0.213 \mathrm{~g}, 0.130 \mathrm{~mL}, 1.00 \mathrm{mmol})$, morpholine (0.104 g, $0.105 \mathrm{~mL}, 1.20 \mathrm{mmol})$, sodium tert-butoxide $(0.134 \mathrm{~g}, 1.40 \mathrm{mmol}), 3$ (37.3 mg, $0.08 \mathrm{mmol}, 8 \mathrm{~mol} \%), \mathrm{Pd}_{2} \mathrm{dba}_{3}(18.3 \mathrm{mg}, 0.02 \mathrm{mmol}, 2 \mathrm{~mol} \%)$ and toluene $(2 \mathrm{~mL})$ was stirred at $80{ }^{\circ} \mathrm{C}$ for $16 \mathrm{~h}$. The crude reaction mixture was purified by flash column chromatography using 1:9 ethyl acetate:hexane, to yield the title compound as a pale yellow solid (0.155 g, 71\%), mp 59-60 ${ }^{\circ} \mathrm{C} .{ }^{1} \mathrm{H}$ NMR $\left(400 \mathrm{MHz} \mathrm{CDCl}_{3}\right): \delta$ 7.84-7.79 (m, $1 \mathrm{H}), 7.78-7.74(\mathrm{~m}, 1 \mathrm{H}), 7.40-7.33(\mathrm{~m}, 2 \mathrm{H}), 6.65(\mathrm{~s}, 1 \mathrm{H}), 3.95(\mathrm{t}, J=4.6 \mathrm{~Hz}, 4 \mathrm{H}), 3.15(\mathrm{t}$, $J=4.6 \mathrm{~Hz}, 4 \mathrm{H}),{ }^{13} \mathrm{C} \mathrm{NMR}\left(100 \mathrm{MHz}_{\mathrm{CDCl}}\right)$ : $\delta 146.9,139.5,134.5,124.8,123.8,123.5$, 121.9, 107.4, 67.3, 53.0. IR (thin film cm${ }^{-1}$ ) 2966, 2861, 2825, 1519, 1449, 1432, 1368, 1356, 1281, 1256, 1192, 1111, 1065, 1017, 899, 860. Anal. Calcd for $\mathrm{C}_{12} \mathrm{H}_{13} \mathrm{NOS}$ : C, 65.72. H, 5.97. Found C, 66.06. H, 6.02.

Methyl-phenyl-pyrimidin-5-yl-amine (Table 2, Entry 1). Following general procedure 1 , a mixture of 5-bromopyrimidine $(0.158 \mathrm{~g}, 1.00 \mathrm{mmol}), N$-methyl aniline $(0.128 \mathrm{~g}$, $0.130 \mathrm{~mL}, 1.20 \mathrm{mmol})$, sodium tert-butoxide $(0.134 \mathrm{~g}, 1.40 \mathrm{mmol}), 1$ (38.0 mg, 0.08 mmol, $8 \mathrm{~mol} \%), \mathrm{Pd}_{2} \mathrm{dba}_{3}(18.3 \mathrm{mg}, 0.02 \mathrm{mmol}, 2 \mathrm{~mol} \%)$ and toluene $(2 \mathrm{~mL})$ was stirred at $100{ }^{\circ} \mathrm{C}$ for $15 \mathrm{~h}$. The crude reaction mixture was purified by flash column chromatography using ethyl acetate to yield the title compound as a pale brown solid (0.175 g, 95\%), mp 74-75 ${ }^{\circ} \mathrm{C} .{ }^{1} \mathrm{H}$ NMR $\left(400 \mathrm{MHz} \mathrm{C}_{6} \mathrm{D}_{6}\right): \delta 9.10(\mathrm{~s}, 1 \mathrm{H}), 8.32(\mathrm{~s}, 2 \mathrm{H})$, $7.11(\mathrm{t}, J=7.7 \mathrm{~Hz}, 2 \mathrm{H}), 6.97(\mathrm{~m}, 1 \mathrm{H}), 6.81(\mathrm{dd}, J=7.6 \mathrm{~Hz}, 0.9 \mathrm{~Hz}, 2 \mathrm{H}), 2.66(\mathrm{~s}, 3 \mathrm{H}) .{ }^{13} \mathrm{C}$ NMR $\left(100 \mathrm{MHz} \mathrm{C}_{6} \mathrm{D}_{6}\right): \delta 150.5 .146 .9,144.6,142.9,130.2,124.9,124.0,39.0$. IR (thin film $\left.\mathrm{cm}^{-1}\right)$. 1569, 1542, 1495, 1441, 1424, 1356, 1273, 1196, 1069, 866, 775, 702. Anal. Calcd for $\mathrm{C}_{11} \mathrm{H}_{11} \mathrm{~N}_{3}$ : C, 71.33. H, 5.99. Found C, 70.94. 6.02.

4-(Pyrimidin-5-ylamino)-benzoic acid ethyl ester (Table 2, Entry 2). Following general procedure 1 , a mixture of 5-bromopyrimidine $(0.158 \mathrm{~g}, 1.00 \mathrm{mmol})$, ethyl-4aminobenzoate $(0.198 \mathrm{~g}, 1.20 \mathrm{mmol}), \mathrm{K}_{3} \mathrm{PO}_{4}(0.297 \mathrm{~g}, 1.40 \mathrm{mmol}), 1$ (38.0 mg, 0.08 mmol, $8 \mathrm{~mol} \%), \mathrm{Pd}_{2} \mathrm{dba}_{3}(18.3 \mathrm{mg}, 0.02 \mathrm{mmol}, 2 \mathrm{~mol} \%)$, and toluene ( $2 \mathrm{~mL}$ ) was stirred $100{ }^{\circ} \mathrm{C}$ for $19 \mathrm{~h}$. The crude reaction mixture was purified by flash column chromatography using ethyl acetate to yield the title compound as a white solid $0.218 \mathrm{~g}$, 90\%), mp 161-162 ${ }^{\circ} \mathrm{C} .{ }^{1} \mathrm{H}$ NMR (400 $\left.\mathrm{MHz} \mathrm{CDCl}_{3}\right): \delta 8.88(\mathrm{~s}, 1 \mathrm{H}), 8.64(\mathrm{~s}, 2 \mathrm{H}), 7.99$ (d, $J=8.7 \mathrm{~Hz}, 2 \mathrm{H}), 7.06(\mathrm{~d}, J=8.7 \mathrm{~Hz}, 2 \mathrm{H}), 6.34(\mathrm{~s}, \mathrm{br}, 1 \mathrm{H}), 4.35(\mathrm{q}, J=7.1 \mathrm{~Hz}, 2 \mathrm{H}), 1.38$ $(\mathrm{t}, J=7.1 \mathrm{~Hz}, 3 \mathrm{H}) .{ }^{13} \mathrm{C}$ NMR $\left(100 \mathrm{MHz} \mathrm{CDCl}_{3}\right): \delta 166.3,152.5,147.3,145.6,136.8$, 131.8, 123.9, 115.9, 61.0, 14.5. IR (thin film cm ${ }^{-1}$ ) 3242, 3054, 1715, 1607, 1576, 1563, 1420, 1328, 1291, 1279, 1179, 1115, 1106, 764, 721. Anal. Calcd for $\mathrm{C}_{13} \mathrm{H}_{13} \mathrm{~N}_{3} \mathrm{O}_{2}$ : C, 61.14. H, 5.86. 

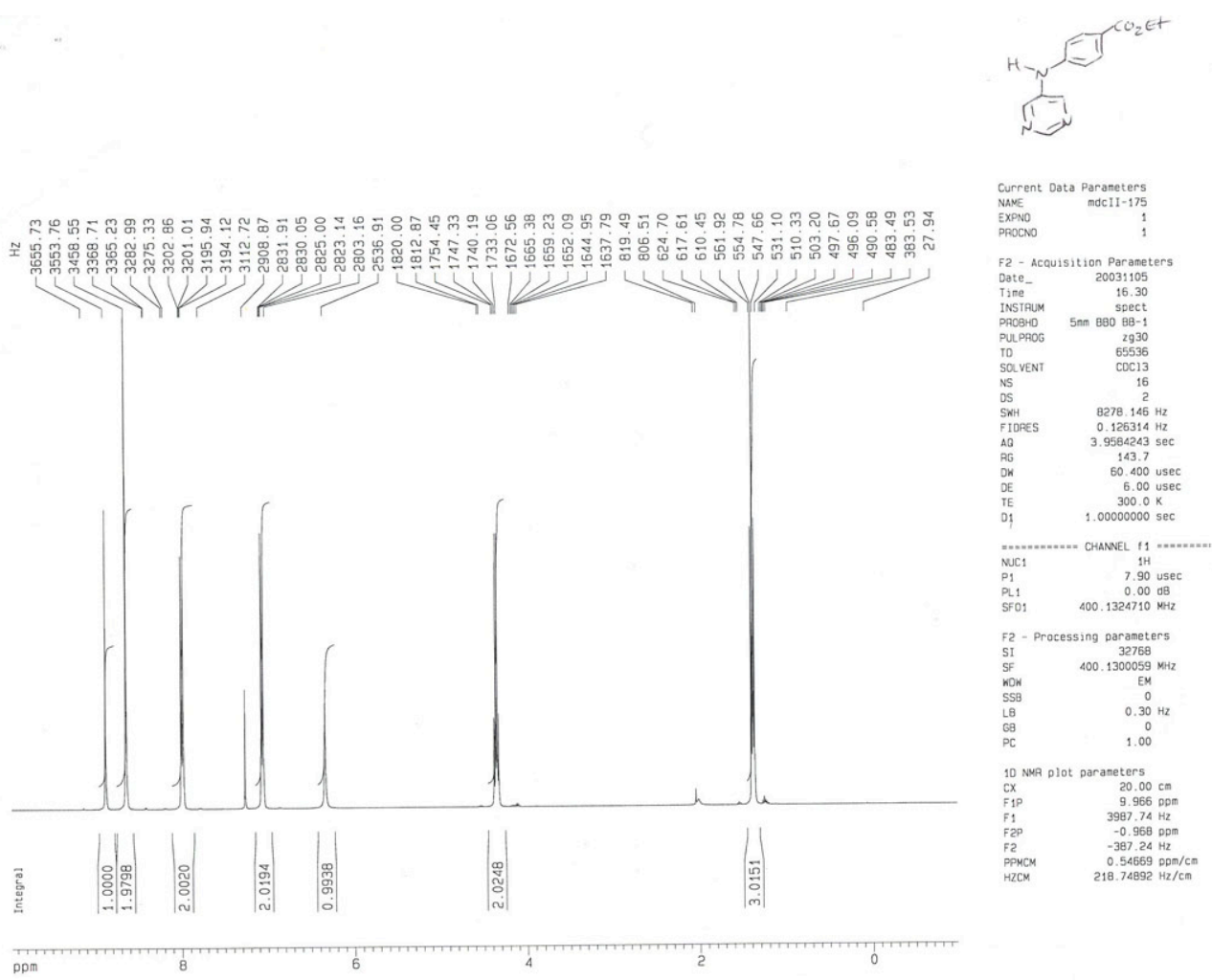

틈
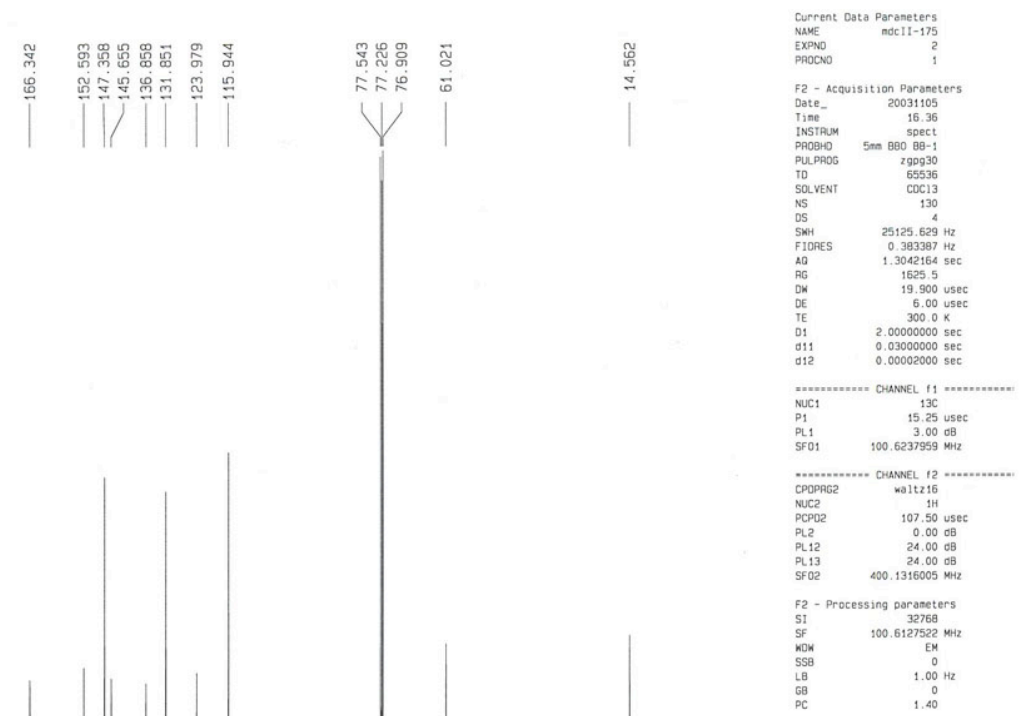

mom

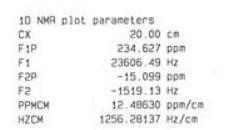


3-(Pyrimidin-5-ylamino-benzonitrile (Table 2, Entry 3). Following general procedure 1, a mixture of 5-bromopyrimidine $(0.158 \mathrm{~g}, 1.00 \mathrm{mmol})$, 4-aminobenzonitrile $(0.141 \mathrm{~g}$, $1.20 \mathrm{mmol}), \mathrm{K}_{3} \mathrm{PO}_{4}(0.297 \mathrm{~g}, 1.40 \mathrm{mmol}), 1$ (38.0 mg, $\left.0.08 \mathrm{mmol}, 8 \mathrm{~mol} \%\right), \mathrm{Pd}_{2} \mathrm{dba}_{3}$ (18.3 mg, $0.02 \mathrm{mmol}, 2 \mathrm{~mol} \%)$ and toluene $(2 \mathrm{~mL})$ was stirred at $100{ }^{\circ} \mathrm{C}$ for $15 \mathrm{~h}$. The crude reaction mixture was purified by flash column chromatography using ethyl acetate to yield the title compound as a white solid $(0.121 \mathrm{~g}, 62 \%), \mathrm{mp} 189-190{ }^{\circ} \mathrm{C} .{ }^{1} \mathrm{H}$ NMR (400 MHz d ${ }_{6}$-DMSO): $\delta 8.89(\mathrm{~s}, 1 \mathrm{H}), 8.75(\mathrm{~s}, 1 \mathrm{H}), 8.64(\mathrm{~s}, 2 \mathrm{H}), 7.55-7.38(\mathrm{~m}, 3 \mathrm{H}), 7.34-$ 7.26 (m, 1H). ${ }^{13} \mathrm{C}$ NMR (100 MHz d -DMSO): $\delta 151.7,146.3,143.6,138.1,131.6,125.1$, 122.2, 119.8, 119.6, 113.7. IR (thin film cm $\mathrm{cm}^{-1}$ ) 3365, 1571, 1530, 1493, 1422, 1333, 1277 , 1192, 849, 791, 717. Anal. Calcd for $\mathrm{C}_{11} \mathrm{H}_{8} \mathrm{~N}_{4}$ : C, 67.34. H, 4.11. Found C, 67.06. H, 4.15 .

Pyrimidin-5-yl-(4-trifluoromethyl-phenyl)-amine (Table 2, Entry 4). Following general procedure 1, a mixture of 5-bromopyrimidine $(0.158 \mathrm{~g}, 1.00 \mathrm{mmol})$, 4aminobenzotrifluoride $(0.193 \mathrm{~g}, 0.150 \mathrm{~mL}, 1.20 \mathrm{mmol}), \mathrm{K}_{3} \mathrm{PO}_{4}(0.297 \mathrm{~g}, 1.40 \mathrm{mmol}), 1$ (38.0 mg, $0.08 \mathrm{mmol}, 8 \mathrm{~mol} \%), \mathrm{Pd}_{2} \mathrm{dba}_{3}(18.3 \mathrm{mg}, 0.02 \mathrm{mmol}, 2 \mathrm{~mol} \%$ ) and toluene (2 $\mathrm{mL}$ ) was stirred at $100{ }^{\circ} \mathrm{C}$ for $15 \mathrm{~h}$. The crude reaction mixture was purified by flash column chromatography, ethyl acetate, to yield the title compound as a white solid $(0.210$ g, 88\%), mp 157-158 ${ }^{\circ} \mathrm{C} .{ }^{1} \mathrm{H}$ NMR $\left(400 \mathrm{MHz} \mathrm{CDCl}_{3}\right): \delta 8.89(\mathrm{~s}, 1 \mathrm{H}), 8.62(\mathrm{~s}, 2 \mathrm{H}), 7.57$ $(\mathrm{d}, J=8.5 \mathrm{~Hz}, 2 \mathrm{H}), 7.12(\mathrm{~d}, J=8.4 \mathrm{~Hz}, 2 \mathrm{H}), 6.00(\mathrm{~s}, \mathrm{br}, 1 \mathrm{H}) .{ }^{13} \mathrm{C}$ NMR $(100 \mathrm{MHz}$ $\left.\mathrm{CDCl}_{3}\right): \delta 152.5,147.1,144.4,137.0,127.35,127.31,127.2,125.6,124.4,124.0,122.9$, 116.7, observed complexity due to ${ }^{19} \mathrm{~F}$ splitting. IR (thin film $\mathrm{cm}^{-1}$ ) 3244, 3095, 3051, $1605,1567,1538,1420,1329,1318,1189,1140,1075,889,849$, 719. Anal. Calcd for $\mathrm{C}_{11} \mathrm{H}_{8} \mathrm{~F}_{3} \mathrm{~N}_{3}$ : C, 55.23. H, 3.37. Found C, 55.11. H, 3.44.

4-Pyrimidin-5-yl-morpholine (Table 2, Entry 5). Following general procedure 1, a mixture of 5-bromopyrimidine $(0.158 \mathrm{~g}, 1.00 \mathrm{mmol})$, morpholine $(0.104 \mathrm{~g}, 0.105 \mathrm{~mL}$, $1.20 \mathrm{mmol})$, sodium tert-butoxide $(0.134 \mathrm{~g}, 1.40 \mathrm{mmol}), 2(32.8 \mathrm{mg}, 0.08 \mathrm{mmol}, 8$ $\mathrm{mol} \%$ ), $\mathrm{Pd}_{2} \mathrm{dba}_{3}(18.3 \mathrm{mg}, 0.02 \mathrm{mmol}, 2 \mathrm{~mol} \%)$ and toluene $(2 \mathrm{~mL})$ was stirred at $100{ }^{\circ} \mathrm{C}$ for $15 \mathrm{~h}$. The crude reaction mixture was purified by flash column chromatography using 98:2 ethyl acetate: $\mathrm{Et}_{3} \mathrm{~N}$ to yield the title compound as a light brown solid $(0.130 \mathrm{~g}, 75 \%)$, mp 38-39 ${ }^{\circ} \mathrm{C} .{ }^{1} \mathrm{H}$ NMR (400 MHz d 6 -DMSO): $\delta 8.61$ (s, 1H), 8.49 (s, 2H), $3.75(\mathrm{t}, J=4.8$ $\mathrm{Hz}, 4 \mathrm{H}), 3.23(\mathrm{t}, J=4.8 \mathrm{~Hz}, 4 \mathrm{H}) .{ }^{13} \mathrm{C}$ NMR (100 MHz d 6 -DMSO): $\delta 149.7,144.9,143.7$, 66.5, 47.4. IR (thin film cm $\mathrm{cm}^{-1}$ ) 2956, 2944, 2927, 2865, 2852, 1569, 1557, 1542, 1443, 1272, 1245, 1119, 924, 719. Anal. Calcd for $\mathrm{C}_{8} \mathrm{H}_{11} \mathrm{~N}_{3} \mathrm{O}: \mathrm{C}$, 58.17. H, 6.71. Found $\mathrm{C}$, 58.28. H, 6.81.

5-Pyrrolidin-1-yl-pyrimidine (Table 2, Entry 6). Following general procedure 1, a mixture of 5-bromopyrimidine $(0.158 \mathrm{~g}, 1.00 \mathrm{mmol})$, pyrrolidine $(0.085 \mathrm{~g}, 0.100 \mathrm{~mL}$, $1.20 \mathrm{mmol}$ ), sodium tert-butoxide (0.134 g, $1.4 \mathrm{mmol}), 1$ (38.0 mg, $0.08 \mathrm{mmol}, 8 \mathrm{~mol} \%)$, $\mathrm{Pd}_{2} \mathrm{dba}_{3}(18.3 \mathrm{mg}, 0.02 \mathrm{mmol}, 2 \mathrm{~mol} \%)$ and toluene $(2 \mathrm{~mL})$ was stirred at $100{ }^{\circ} \mathrm{C}$ for $15 \mathrm{~h}$. The crude reaction mixture was purified by flash column chromatography using ethyl acetate to yield the title compound as a pale yellow solid $(0.070 \mathrm{~g}, 48 \%), \mathrm{mp} 73-75{ }^{\circ} \mathrm{C}$. ${ }^{1} \mathrm{H}$ NMR (400 MHz CDCl$\left.)_{3}\right): \delta 8.54(\mathrm{~s}, 1 \mathrm{H}), 8.04(\mathrm{~s}, 2 \mathrm{H}), 3.31(\mathrm{t}, J=6.5 \mathrm{~Hz}, 4 \mathrm{H}), 2.05$ $(\mathrm{m}, 4 \mathrm{H}) .{ }^{13} \mathrm{C} \mathrm{NMR}\left(100 \mathrm{MHz} \mathrm{CDCl}_{3}\right): \delta 146.8,141.3,139.5,47.0,25.5$. IR (thin film cm ${ }^{-}$ 
$\left.{ }^{1}\right) 2850,1569,1437,1337,1198,1156,868,727$. Anal. Calcd for $\mathrm{C}_{8} \mathrm{H}_{11} \mathrm{~N}_{3}: \mathrm{C}, 64.40 . \mathrm{H}$, 7.43. Found C, 64.73. H, 7.32.

(2-Methyl-benzothiazol-5-yl)-p-tolyl-amine (Table 3, Entry 1). Following general procedure 1, a mixture of 2-methyl-5-chlorobenzothiazole $(0.183 \mathrm{~g}, 1.00 \mathrm{mmol})$, 4methyl aniline $(0.128 \mathrm{~g}, 1.20 \mathrm{mmol})$, sodium tert-butoxide $(0.134 \mathrm{~g}, 1.40 \mathrm{mmol}), 1(38.0$ $\mathrm{mg}, 0.08 \mathrm{mmol}, 8 \mathrm{~mol} \%), \mathrm{Pd}_{2} \mathrm{dba}_{3}(18.3 \mathrm{mg}, 0.02 \mathrm{mmol}, 2 \mathrm{~mol} \%)$ and toluene $(2 \mathrm{~mL})$ was stirred at $90{ }^{\circ} \mathrm{C}$ for $18 \mathrm{~h}$. The crude reaction mixture was purified by flash column chromatography using 1:1 ethyl acetate:hexane to yield the title compound as a pale brown solid (0.250 g, 98\%), mp 157-158 $\left.{ }^{\circ} \mathrm{C} .{ }^{1} \mathrm{H} \mathrm{NMR} \mathrm{(400} \mathrm{MHz} \mathrm{CDCl}_{3}\right)$ : $\delta$ 7.65-7.62 (m, 2H), 7.11-7.03 (m, 5H), 5.75 (s, br, 1H), 2.81 (s, 3H), 2.32 (s, 3H). ${ }^{13} \mathrm{C}$ NMR $(100 \mathrm{MHz}$ $\left.\mathrm{CDCl}_{3}\right): \delta 168.1,154.9,142.9,140.4,131.2,130.0,127.2,121.8 .118 .9,116.4,109.5$, 20.8, 20.3. IR (thin film cm $\mathrm{cm}^{-1}$ ) 3292, 3116, 1617, 1600, 1530, 1515, 1457, 1339, 1314, 1301, 1241, 1179, 1167, 814, 791. Anal. Calcd for $\mathrm{C}_{15} \mathrm{H}_{14} \mathrm{~N}_{2} \mathrm{~S}$ : C, 70.83. H, 5.55.

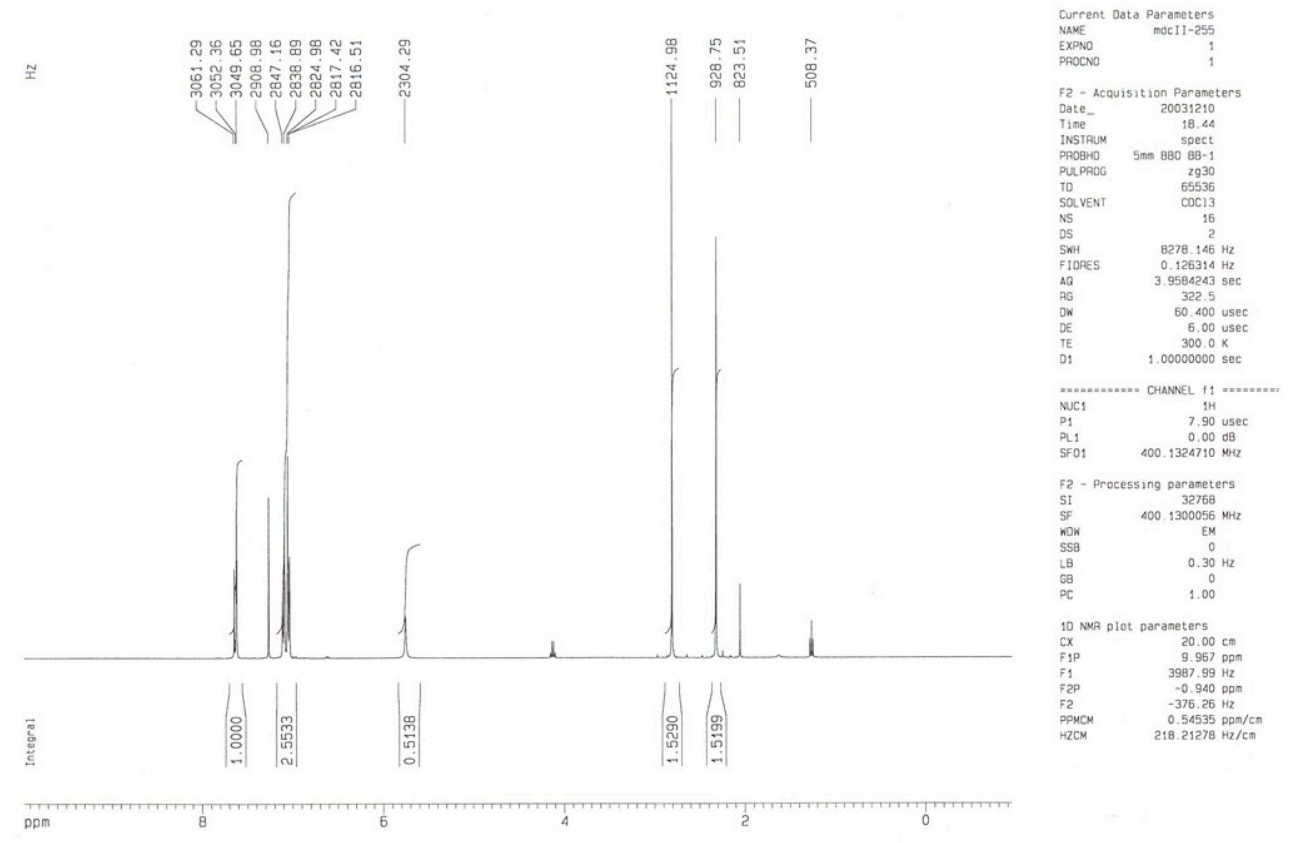




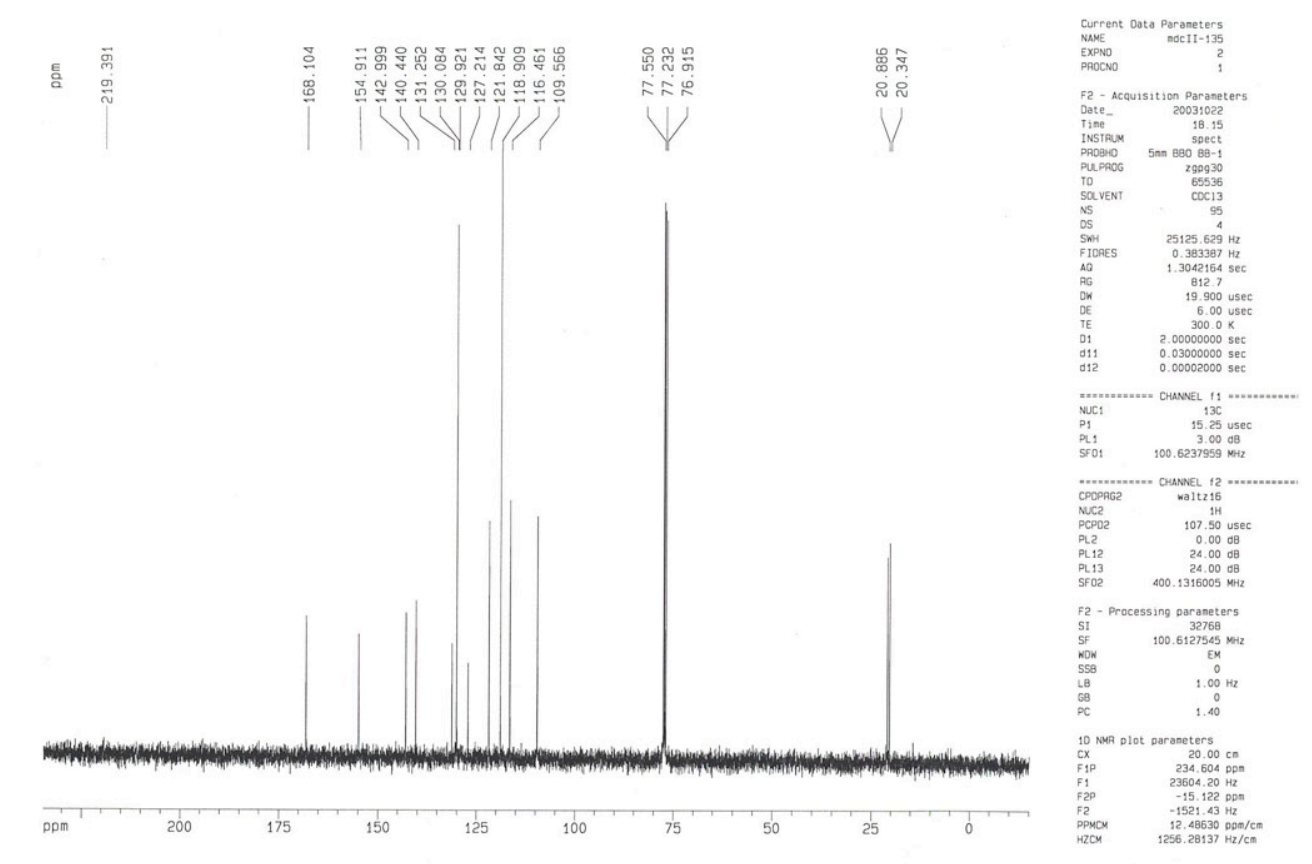

2-Methyl-5-morpholin-4-yl-benzothiazole (Table 3, Entry 2). Following general procedure 1, a mixture of 2-methyl-5-chlorobenzothiazole $(0.183 \mathrm{~g}, 1.00 \mathrm{mmol})$, morpholine $(0.104 \mathrm{~g}, 0.105,1.20 \mathrm{mmol})$, sodium tert-butoxide $(0.134 \mathrm{~g}, 1.40 \mathrm{mmol}), 1$ (38.0 mg, $0.08 \mathrm{mmol}, 8 \mathrm{~mol} \%$ ), $\mathrm{Pd}_{2} \mathrm{dba}_{3}(18.3 \mathrm{mg}, 0.02 \mathrm{mmol}, 2 \mathrm{~mol} \%$ ) and toluene (2 $\mathrm{mL}$ ) was stirred at $90{ }^{\circ} \mathrm{C}$ for $15 \mathrm{~h}$. The crude reaction mixture was purified by flash column chromatography using $1: 1$ ethyl acetate:hexane to yield the title compound as a white solid (0.152 g, 65\%), mp 95-96 ${ }^{\circ} \mathrm{C}$. ${ }^{1} \mathrm{H} \mathrm{NMR} \mathrm{(400} \mathrm{MHz}_{\mathrm{CDCl}}$ ): $\delta 7.66(\mathrm{~d}, J=8.8$ $\mathrm{Hz}, 1 \mathrm{H}), 7.44(\mathrm{~d}, J=2.2 \mathrm{~Hz}, 1 \mathrm{H}), 7.03(\mathrm{dd}, J=8.8 \mathrm{~Hz}, 2.3 \mathrm{~Hz}, 1 \mathrm{H}), 3.89$ (t, $J=4.7 \mathrm{~Hz}$, $4 \mathrm{H}), 3.19$ (t, $J=4.7 \mathrm{~Hz}, 4 \mathrm{H}), 2.79(\mathrm{~s}, 3 \mathrm{H}) .{ }^{13} \mathrm{C} \mathrm{NMR}\left(100 \mathrm{MHz} \mathrm{CDCl}_{3}\right): \delta 168.0,154.9$, $150.7,127.1,121.6,115.7,108.6,67.0,50.2,20.3$. IR (thin film $\mathrm{cm}^{-1}$ ) 2964, 2954, 2852, 1470, 1459, 1445, 1268, 1250, 1189, 1169, 1115, 1040, 957, 891, 847, 814, 796. Anal. Calcd for $\mathrm{C}_{12} \mathrm{H}_{14} \mathrm{~N}_{2} \mathrm{OS}$ : C, 61.51. H, 6.02. Found C, 61.49. H, 6.05.

2-Piperidin-1-yl-benzothiazole (Table 3, Entry 3). Following general procedure 1, a mixture of 2-chlorobenzothiazole $(0.169 \mathrm{~g}, 0.130 \mathrm{~mL}, 1.00 \mathrm{mmol})$, piperidine $(0.102 \mathrm{~g}$, $0.118 \mathrm{~mL}, 1.20 \mathrm{mmol})$, sodium tert-butoxide $(0.134 \mathrm{~g}, 1.40 \mathrm{mmol}), 2(8.2 \mathrm{mg}, 0.02$ mmol, $2 \mathrm{~mol} \%$ ), $\mathrm{Pd}_{2} \mathrm{dba}_{3}(4.5 \mathrm{mg}, 0.005 \mathrm{mmol}, 0.5 \mathrm{~mol} \%$ ) and toluene ( $2 \mathrm{~mL}$ ) was stirred at $25{ }^{\circ} \mathrm{C}$ for $24 \mathrm{~h}$. The crude reaction mixture was purified by flash column chromatography using 1:1 ethyl acetate:hexane to yield the title compound as a white solid (0.205 g, 94\%), mp 93-94 ${ }^{\circ} \mathrm{C} .{ }^{1} \mathrm{H}$ NMR (400 $\left.\mathrm{MHz} \mathrm{CDCl}_{3}\right): \delta 7.59$ (dd, $J=7.8 \mathrm{~Hz}$, $0.8 \mathrm{~Hz}, 1 \mathrm{H}), 7.55-7.53(\mathrm{~m}, 1 \mathrm{H}), 7.30-7.26(\mathrm{~m}, 1 \mathrm{H}), 7.05(\mathrm{~m}, 1 \mathrm{H}), 3.60(\mathrm{~m}, 4 \mathrm{H}), 1.70(\mathrm{~s}$, $6 \mathrm{H}) .{ }^{13} \mathrm{C} \mathrm{NMR}\left(100 \mathrm{MHz} \mathrm{CDCl}_{3}\right): \delta 169.1,153.1,130.8,126.0,121.2,120.7,118.9,49.8$, 
25.5, 24.4. IR (thin film cm $\mathrm{cm}^{-1}$ ) 2941, 2921, 2850, 1534, 1524, 1333, 1287, 1258, 1239, 1212, 1121, 1009, 901, 760. Anal. Calcd for $\mathrm{C}_{12} \mathrm{H}_{14} \mathrm{~N}_{2} \mathrm{~S}$ : C, 66.02. H, 6.46. Found C, 65.84. H, 6.45.

Benzothiazol-2-yl-dibutyl-amine (Table 3, Entry 4). ${ }^{2}$ Following general procedure 1. a mixture of 2-chlorobenzothiazole $(0.169 \mathrm{~g}, 0.130 \mathrm{~mL}, 1.00 \mathrm{mmol})$, di- $n$-butylamine $(0.155 \mathrm{~g}, 0.202 \mathrm{~mL}, 1.20 \mathrm{mmol})$, sodium tert-butoxide $(0.134 \mathrm{~g}, 1.40 \mathrm{mmol}), 3$ (37.3 mg, $0.08 \mathrm{mmol}, 8 \mathrm{~mol} \%), \mathrm{Pd}_{2} \mathrm{dba}_{3}(18.2 \mathrm{mg}, 0.02 \mathrm{mmol}, 2 \mathrm{~mol} \%)$ and toluene $(2 \mathrm{~mL})$ was stirred at $80{ }^{\circ} \mathrm{C}$ for $16 \mathrm{~h}$. The crude reaction mixture was purified by flash column chromatography using 1:20 ethyl acetate:hexane to yield the title compound as a yellow oil (0.242 g, 93\%). ${ }^{1} \mathrm{H}$ NMR (400 $\left.\mathrm{MHz} \mathrm{CDCl}_{3}\right): \delta 7.57(\mathrm{dd}, J=7.8 \mathrm{~Hz}, 0.8 \mathrm{~Hz}, 1 \mathrm{H}), 7.53$ $(\mathrm{d}, J=8.0 \mathrm{~Hz}, 1 \mathrm{H}), 7.29-7.25(\mathrm{~m}, 1 \mathrm{H}), 7.05-7.01(\mathrm{~m}, 1 \mathrm{H}), 3.51(\mathrm{t}, J=7.5 \mathrm{~Hz}, 4 \mathrm{H}), 1.73$ $(\mathrm{m}, 4 \mathrm{H}), 1.40$ (sextet, $J=14.9 \mathrm{~Hz}, 7.4 \mathrm{~Hz}, 4 \mathrm{H}), 0.98(\mathrm{t}, J=7.3 \mathrm{~Hz}, 6 \mathrm{H}) .{ }^{13} \mathrm{C}$ NMR $(100$ $\left.\mathrm{MHz} \mathrm{CDCl}_{3}\right): \delta 168.0,153.5,130.8,125.9,120.7,120.6,118.6,51.1,29.8,20.3,14.1$. IR (thin film cm $\mathrm{cm}^{-1}$ ) 2958, 2931, 2871, 1598, 1563, 1536, 1455, 1443, 1372, 1316, 1279, 1210, 1123, 1111, 1067, 1017, 748. Anal. Calcd for $\mathrm{C}_{15} \mathrm{H}_{22} \mathrm{~N}_{2} \mathrm{~S}: \mathrm{C}, 68.66$. H, 8.45.

2-Indol-1-yl-benzothiazole (Table 3, Entry 5). Following general procedure 1, a mixture of 2-chlorobenzothiazole $(0.169 \mathrm{~g}, 0.130 \mathrm{~mL}, 1.00 \mathrm{mmol})$, indole $(0.140 \mathrm{~g}, 1.20$ mmol), sodium tert-butoxide (0.134 g, $1.40 \mathrm{mmol}), 1$ (19.0 mg, $0.04 \mathrm{mmol}, 4 \mathrm{~mol} \%)$, $\mathrm{Pd}_{2} \mathrm{dba}_{3}(9.1 \mathrm{mg}, 0.01 \mathrm{mmol}, 1 \mathrm{~mol} \%)$ and toluene $(2 \mathrm{~mL})$ was stirred at $70{ }^{\circ} \mathrm{C}$ for $15 \mathrm{~h}$. The crude reaction mixture was purified by flash column chromatography using 1:9 ethyl acetate:hexane to yield the title compound as a white solid $(0.190 \mathrm{~g}, 76 \%)$, mp 107-108 ${ }^{\circ} \mathrm{C} .{ }^{1} \mathrm{H}$ NMR $\left(400 \mathrm{MHz} \mathrm{CDCl}_{3}\right): \delta 8.51(\mathrm{~d}, J=8.3 \mathrm{~Hz}, 1 \mathrm{H}), 7.85(\mathrm{~d}, J=8.0 \mathrm{~Hz}, 1 \mathrm{H})$, 7.69, (d, $J=7.9 \mathrm{~Hz}, 1 \mathrm{H}), 7.57-7.54(\mathrm{~m}, 2 \mathrm{H}), 7.39-7.31(\mathrm{~m}, 2 \mathrm{H}), 7.24-7.13(\mathrm{~m}, 2 \mathrm{H}), 6.64$ $(\mathrm{d}, J=3.2 \mathrm{~Hz}, 1 \mathrm{H}) .{ }^{13} \mathrm{C} \mathrm{NMR}\left(100 \mathrm{MHz} \mathrm{CDCl}_{3}\right): \delta 159.0,151.4,135.6,131.6,130.5$, 126.7, 126.6, 124.6, 124.4, 122.9, 122.1, 121.4, 121.3, 114.5, 108.3. IR (thin film $\mathrm{cm}^{-1}$ ) $1528,1472,1449,1439,1351,1333,1206,1140,1013,916$. Anal. Calcd for $\mathrm{C}_{15} \mathrm{H}_{10} \mathrm{~N}_{2} \mathrm{~S}$ : C, 71.97. H, 4.03. Found C, 71.66. H, 4.05.

Methyl-(2-methyl-benzooxazol-5-yl)phenyl-amine (Table 3, Entry 6). Following general procedure 1, a mixture of 2-methyl-5-chlorobenzoxazole $(0.167 \mathrm{~g}, 1.00 \mathrm{mmol})$, $N$-methylaniline $(0.128 \mathrm{~g}, 0.130 \mathrm{~mL}, 1.20 \mathrm{mmol})$, sodium tert-butoxide $(0.134 \mathrm{~g}, 1.40$ mmol), 1 (38.0 mg, $0.08 \mathrm{mmol}, 8 \mathrm{~mol} \%$ ), $\mathrm{Pd}_{2} \mathrm{dba}_{3}$ (18.3 mg, $0.02 \mathrm{mmol}, 2 \mathrm{~mol} \%$ ) and toluene $(2 \mathrm{~mL})$ was stirred at $100{ }^{\circ} \mathrm{C}$ for $15 \mathrm{~h}$. The crude reaction mixture was purified by flash column chromatography using 1:4 ethyl acetate:hexane to yield the title compound as a brown oily solid (0.181 g, 79\%). ${ }^{1} \mathrm{H}$ NMR (400 $\left.\mathrm{MHz} \mathrm{CDCl}_{3}\right): \delta 7.30(\mathrm{~d}, J=2.1 \mathrm{~Hz}$, $1 \mathrm{H}), 7.28(\mathrm{~d}, J=8.7 \mathrm{~Hz}, 1 \mathrm{H}), 7.15-7.10(\mathrm{~m}, 2 \mathrm{H}), 6.95(\mathrm{dd}, J=8.6 \mathrm{~Hz}, 2.2 \mathrm{~Hz}, 1 \mathrm{H}), 6.79-$ $6.74(\mathrm{~m}, 3 \mathrm{H}), 3.23(\mathrm{~s}, 3 \mathrm{H}), 2.52(\mathrm{~s}, 3 \mathrm{H}) .{ }^{13} \mathrm{C}$ NMR $\left(100 \mathrm{MHz} \mathrm{CDCl}_{3}\right): \delta 164.7,149.7$, $147.5,146.1,142.7,129.2,121.2,119.7,117.5,114.3,110.6,41.0,14.7$. IR (thin film cm $\left.{ }^{1}\right) 3062,3037,3027,2948,2875,2809,1598,1576,1495,1453,1341,1297,1256,1200$, 1169, 1113, 1057, 943. Anal. Calcd for $\mathrm{C}_{15} \mathrm{H}_{14} \mathrm{~N}_{2} \mathrm{O}$ : C, 75.61. H, 5.92. Found C, 75.80. H, 5.84 .

2-Phenyl-5-piperidin-1-yl-benzooxazole (Table 3, Entry 7). Following general procedure 1 , a mixture of 2-phenyl-5-chlorobenzoxazole $(0.229 \mathrm{~g}, 1.00 \mathrm{mmol})$, piperidine 
(0.102 g, $0.118 \mathrm{~mL}, 1.20 \mathrm{mmol})$, sodium tert-butoxide (0.134 g, $1.40 \mathrm{mmol}), 1$ (38.0 mg, $0.08 \mathrm{mmol}, 8 \mathrm{~mol} \%), \mathrm{Pd}_{2} \mathrm{dba}_{3}(18.3 \mathrm{mg}, 0.02 \mathrm{mmol}, 2 \mathrm{~mol} \%)$ and toluene $(2 \mathrm{~mL})$ was stirred at $70{ }^{\circ} \mathrm{C}$ for $15 \mathrm{~h}$. The crude reaction mixture was purified by flash column chromatography using 1:9 ethyl acetate:hexane to yield the title compound as a white solid (0.260 g, 94\%), mp 130-131 ${ }^{\circ} \mathrm{C} .{ }^{1} \mathrm{H} \mathrm{NMR}\left(400 \mathrm{MHz} \mathrm{CDCl}_{3}\right): \delta 8.25-8.21(\mathrm{~m}, 2 \mathrm{H})$, 7.54-7.51 (m, 3H), $7.45(\mathrm{~d}, J=8.8 \mathrm{~Hz}, 1 \mathrm{H}), 7.30(\mathrm{~d}, J=2.3 \mathrm{~Hz}, 1 \mathrm{H}), 7.06(\mathrm{dd}, J=8.9$ $\mathrm{Hz}, 2.4 \mathrm{~Hz}, 1 \mathrm{H}), 3.16(\mathrm{t}, J=5.4 \mathrm{~Hz}, 4 \mathrm{H}), 1.80-1.74(\mathrm{~m}, 4 \mathrm{H}), 1.62-1.57(\mathrm{~m}, 2 \mathrm{H}) .{ }^{13} \mathrm{C}$ NMR (100 MHz C $\left.\mathrm{D}_{6}\right)$ : $\delta 163.7,151.6,145.9,144.1,131.2,129.1,128.3,128.1,117.6$, 110.6, 108.3, 52.5, 26.5, 24.6. IR (thin film cm $\mathrm{cm}^{-1}$ ) 2931, 2912, 1551, 1478, 1449, 1439 , 1219, 1204, 1177, 1119, 1057, 1025, 926. Anal. Calcd for $\mathrm{C}_{18} \mathrm{H}_{18} \mathrm{~N}_{2} \mathrm{O}: \mathrm{C}$, 77.67. H, 6.52.
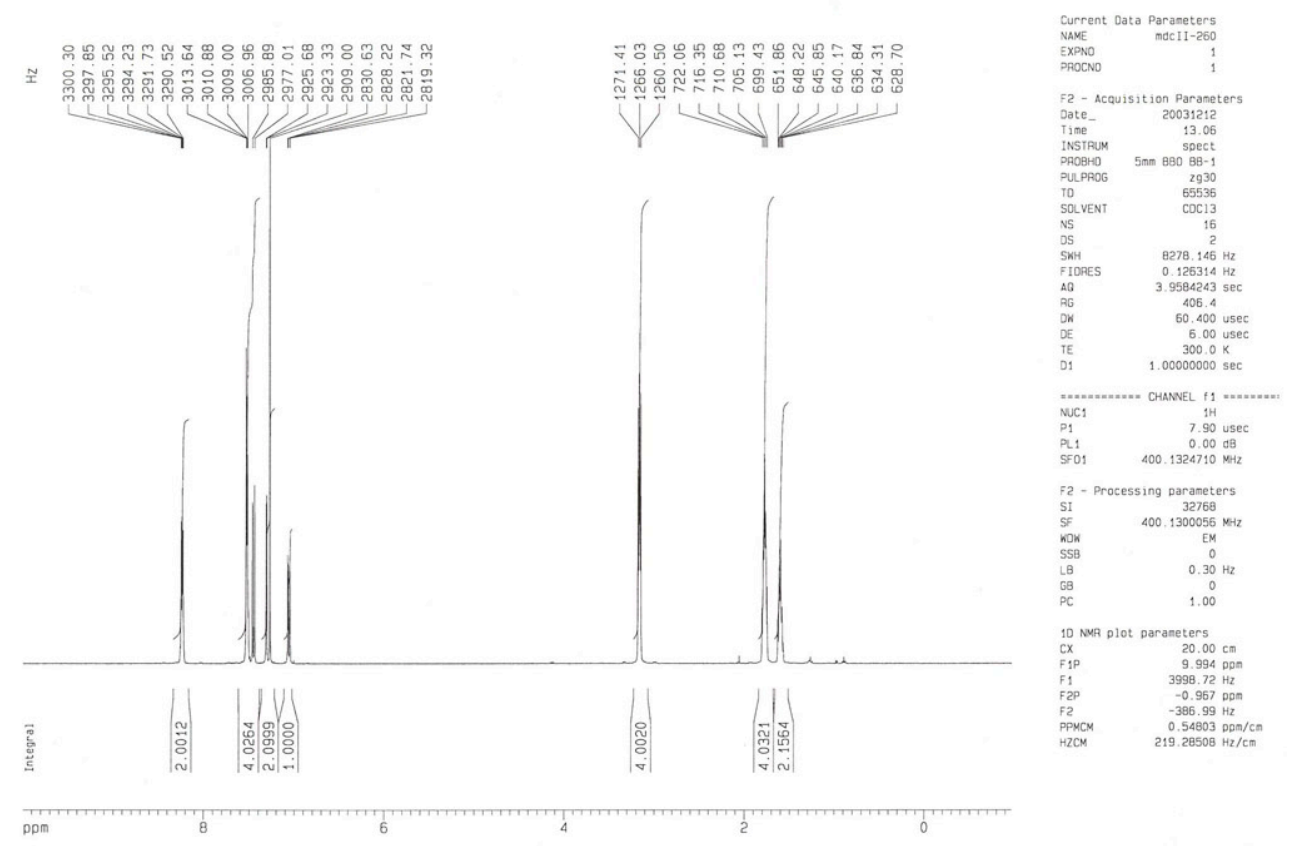

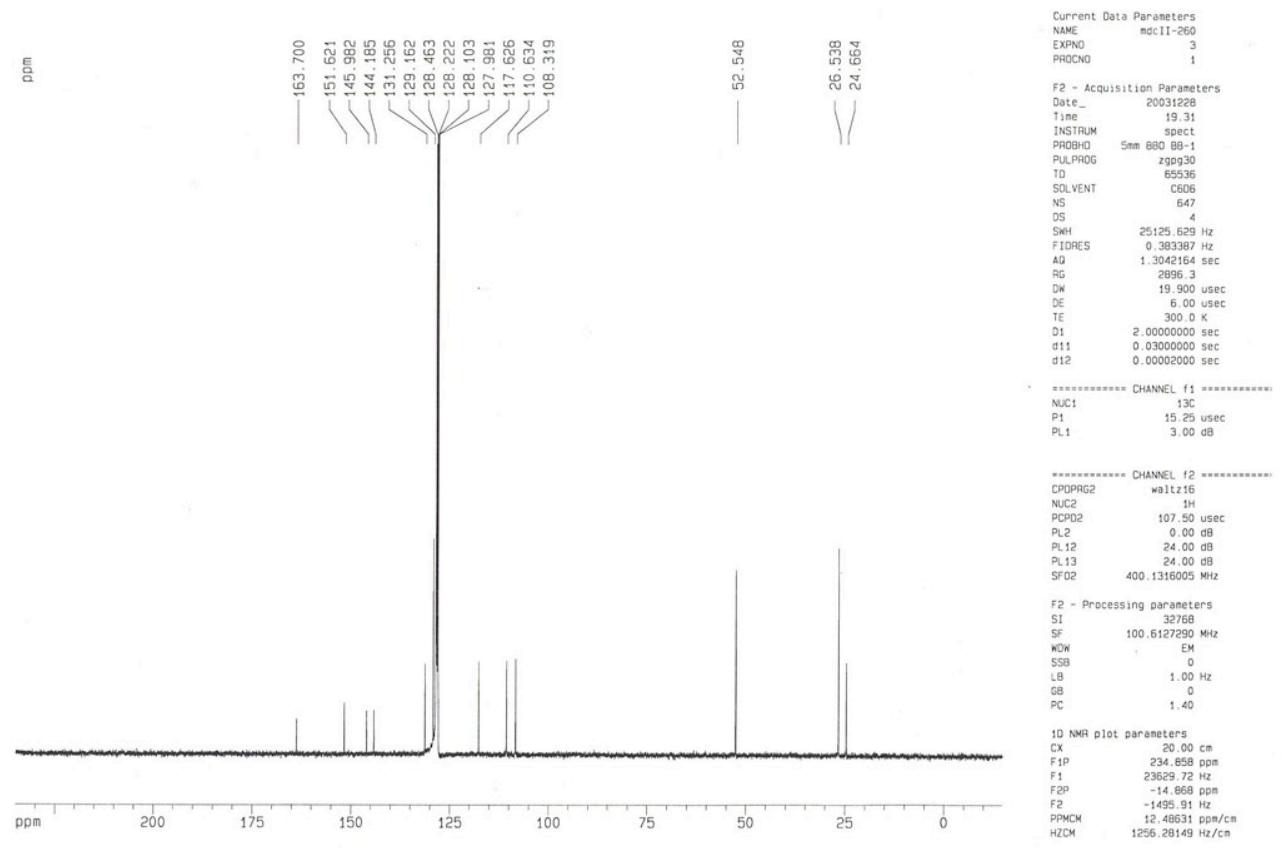

3-(2-Methyl-benzooxazol-5-ylamino)-benzonitrile (Table 3, Entry 8). Following general procedure 1, a mixture of 2-methyl-5-chlorobenzoxazole $(0.167 \mathrm{~g}, 1.00 \mathrm{mmol})$, 3aminobenzonitrile $(0.141 \mathrm{~g}, 1.20 \mathrm{mmol}), \mathrm{K}_{3} \mathrm{PO}_{4}(0.297 \mathrm{~g}, 1.40 \mathrm{mmol}), 1$ (38.0 mg, 0.08 mmol, $8 \mathrm{~mol} \%), \mathrm{Pd}_{2} \mathrm{dba}_{3}(18.3 \mathrm{mg}, 0.02 \mathrm{mmol}, 2 \mathrm{~mol} \%)$ and toluene ( $2 \mathrm{~mL}$ ) was stirred at $100{ }^{\circ} \mathrm{C}$ for $15 \mathrm{~h}$. The crude reaction mixture was purified by flash column chromatography using 1:1 ethyl acetate:hexane to yield the title compound as a white solid $(0.147 \mathrm{~g}, 60 \%), \mathrm{mp} 133-134{ }^{\circ} \mathrm{C} .{ }^{1} \mathrm{H}$ NMR (400 $\left.\mathrm{MHz} \mathrm{CDCl}_{3}\right): \delta 7.43-7.40(\mathrm{~m}, 2 \mathrm{H})$, $7.27(\mathrm{t}, J=7.8 \mathrm{~Hz}, 1 \mathrm{H}), 7.16-7.06(\mathrm{~m}, 4 \mathrm{H}), 6.02(\mathrm{~s}, \mathrm{br}, 1 \mathrm{H}), 2.63(\mathrm{~s}, 3 \mathrm{H}),{ }^{13} \mathrm{C} \mathrm{NMR}(100$ $\left.\mathrm{MHz} \mathrm{CDCl}_{3}\right): \delta 165.2,147.8,145.8,142.8,137.6,130.3,123.2,119.7,119.2,119.1$, 117.9, 113.2, 112.3, 111.0, 14.8. IR (thin film cm $\mathrm{cm}^{-1}$ ) 3928, 1603, 1574, 1559, 1490, 1478, 1437, 1343, 1275, 1187, 1171, 937. Anal. Calcd for $\mathrm{C}_{15} \mathrm{H}_{11} \mathrm{~N}_{3} \mathrm{O}: \mathrm{C}, 72.28$. H, 4.45. 

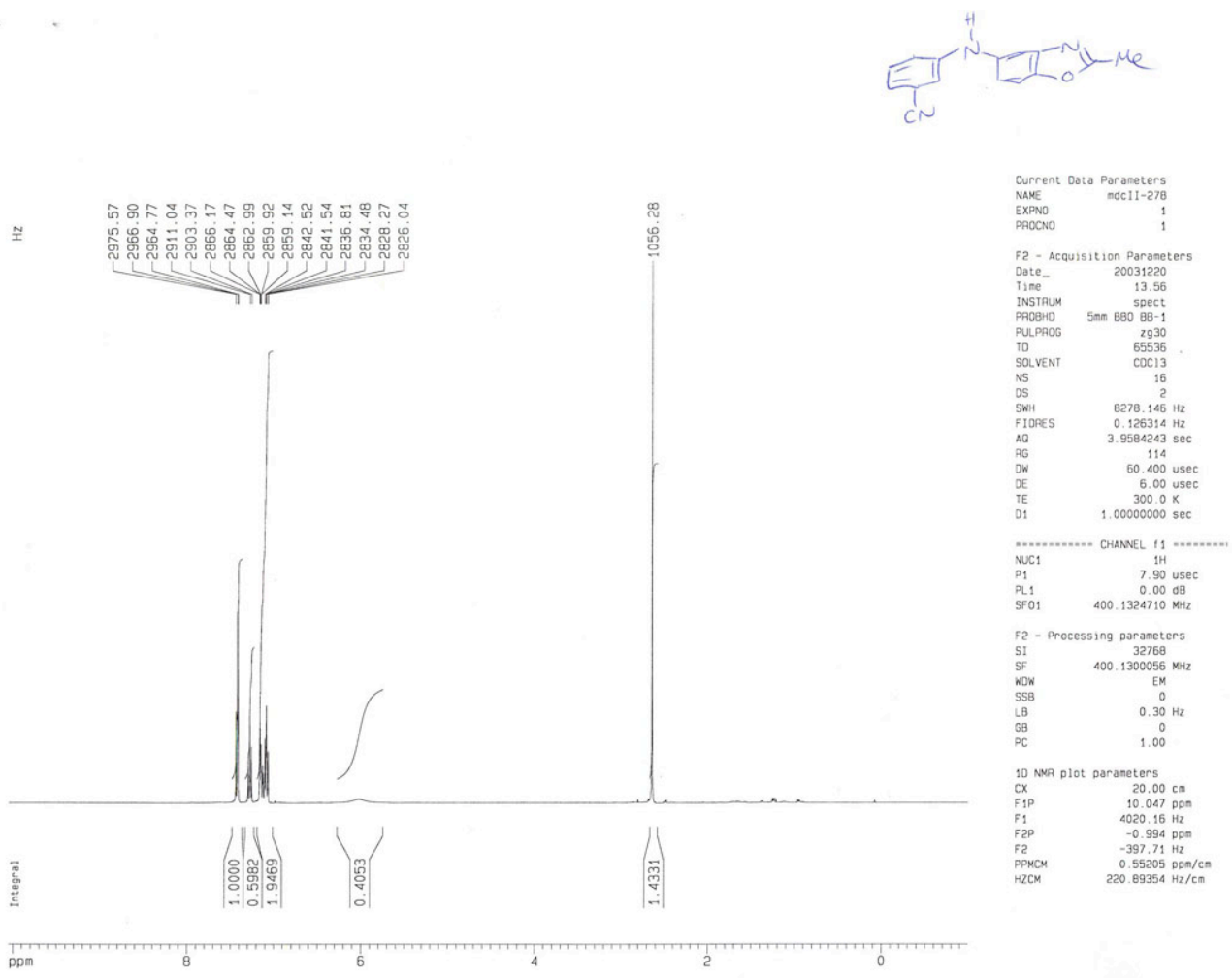

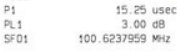

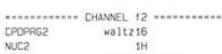

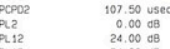

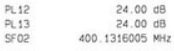

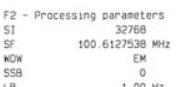

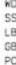

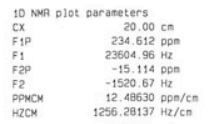


(1H-Indol-5-yl)-phenyl-amine (Table 4, Entry 1). Following general procedure 2, a mixture of 5-bromoindole $(0.196 \mathrm{~g}, 1.00 \mathrm{mmol})$, aniline $(0.111 \mathrm{~g}, 0.109 \mathrm{~mL}, 1.20 \mathrm{mmol})$, lithium bis(trimethylsilyl)amide $(2.20 \mathrm{~mL}, 1.0 \mathrm{M}$ solution in THF, $2.20 \mathrm{mmol}), 4(9.4$ $\mathrm{mg}, 0.024 \mathrm{mmol}, 2.4 \mathrm{~mol} \%), \mathrm{Pd}_{2} \mathrm{dba}_{3}(9.1 \mathrm{mg}, 0.01 \mathrm{mmol}, 1 \mathrm{~mol} \%)$ and THF (1 mL) was stirred at $65{ }^{\circ} \mathrm{C}$ for $24 \mathrm{~h}$. The crude reaction mixture was purified by flash column chromatography using 1:3 ethyl acetate:hexane to yield the title compound as a grey solid (0.201 g, 97\%), mp 97-98 ${ }^{\circ} \mathrm{C} .{ }^{1} \mathrm{H}$ NMR $\left(400 \mathrm{MHz} \mathrm{CDCl}_{3}\right): \delta 8.09$ (s, br, $\left.1 \mathrm{H}\right), 7.45$ (d, $J=$ $2.0 \mathrm{~Hz}, 1 \mathrm{H}), 7.35(\mathrm{~d}, J=8.5 \mathrm{~Hz}, 1 \mathrm{H}), 7.26-7.20(\mathrm{~m}, 3 \mathrm{H}), 7.06(\mathrm{dd}, J=8.5 \mathrm{~Hz}, 2.0 \mathrm{~Hz}$, $1 \mathrm{H})$, 6.97-6.95 (m, 2H), 6.86-6.82 (m, 1H), 6.51-6.50 (m, 1H), 5.65 (s, br, $1 \mathrm{H}) .{ }^{13} \mathrm{C}$ NMR $\left(100 \mathrm{MHz} \mathrm{CDCl}_{3}\right): \delta 146.4,135.2,132.8,129.4,128.7,125.1,119.2,118.4,115.4,113.3$, 111.8, 102.5. IR (thin film cm $\mathrm{cm}^{-1}$ ) 3411, 3398, 3384, 3371, 1600, 1520, 1495, 1459, 1306, 1285, 1154, 876, 746. Anal. Calcd for $\mathrm{C}_{14} \mathrm{H}_{12} \mathrm{~N}_{2}$ : C, 80.74. H, 5.81.

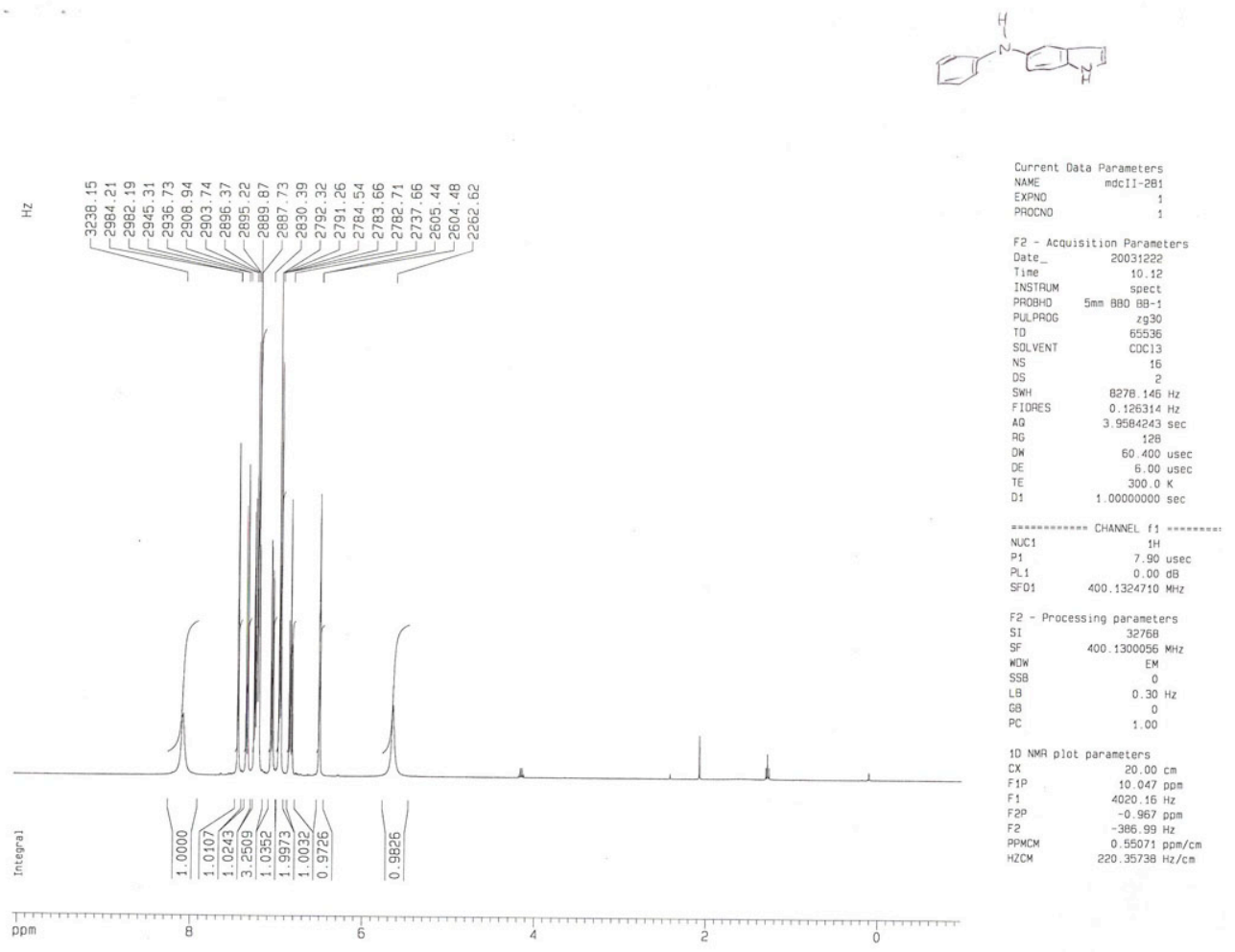




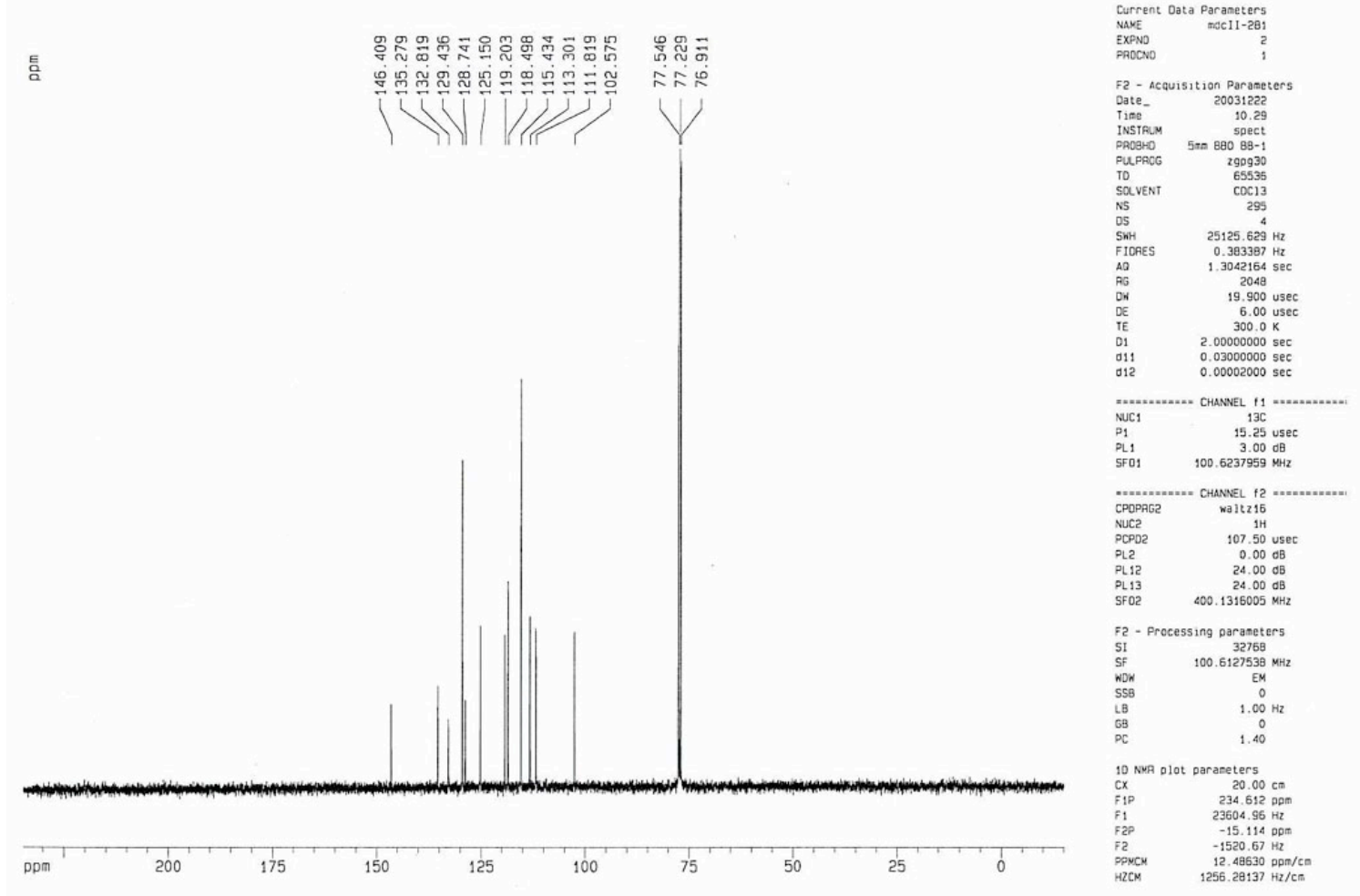

5-Morpholin-4-yl-1H -indole (Table 4, Entry 2). Following general procedure 2, a mixture of 5-bromoindole $(0.196 \mathrm{~g}, 1.00 \mathrm{mmol})$, morpholine $(0.104 \mathrm{~g}, 0.105 \mathrm{~mL}, 1.20$ mmol), lithium bis(trimethylsilyl)amide (2.20 mL, 1.0 M solution in THF, $2.20 \mathrm{mmol}), 4$ (9.4 mg, $0.024 \mathrm{mmol}, 2.4 \mathrm{~mol} \%), \mathrm{Pd}_{2} \mathrm{dba}_{3}(9.1 \mathrm{mg}, 0.01 \mathrm{mmol}, 1 \mathrm{~mol} \%)$ and THF ( $\left.1 \mathrm{~mL}\right)$ was stirred at $65{ }^{\circ} \mathrm{C}$ for $24 \mathrm{~h}$. The crude reaction mixture was purified by flash column chromatography using 3:1 ethyl acetate:hexane to yield the title compound as a white solid (0.190 g, 94\%), mp 134-135 ${ }^{\circ} \mathrm{C} .{ }^{1} \mathrm{H}$ NMR (400 $\mathrm{MHz} \mathrm{CDCl}_{3}$ ): $\delta 8.31$ (s, br, $\left.1 \mathrm{H}\right)$, $7.33(\mathrm{~d}, J=8.79 \mathrm{~Hz}, 1 \mathrm{H}), 7.19-7.18(\mathrm{~m}, 2 \mathrm{H}), 6.97(\mathrm{dd}, J=8.7 \mathrm{~Hz}, 1.9 \mathrm{~Hz}, 1 \mathrm{H}), 6.49$ (s, $1 \mathrm{H}), 3.92(\mathrm{t}, J=4.3 \mathrm{~Hz}, 4 \mathrm{H}), 3.15(\mathrm{t}, J=4.4 \mathrm{~Hz}, 4 \mathrm{H}) \cdot{ }^{13} \mathrm{C} \mathrm{NMR}\left(100 \mathrm{MHz} \mathrm{CDCl}_{3}\right): \delta$ 145.8, 131.6, 128.4, 124.9, 115.3, 111.7, 107.5, 102.3, 67.3, 52.1. IR (thin film $\mathrm{cm}^{-1}$ ) 3346, 2815, 1476, 1447, 1304, 1275, 1260, 1227, 1165, 1111, 1067, 1044, 960, 893, 837, 758. Anal. Calcd for $\mathrm{C}_{12} \mathrm{H}_{14} \mathrm{~N}_{2} \mathrm{O}: \mathrm{C}, 71.26$. H, 6.98. 


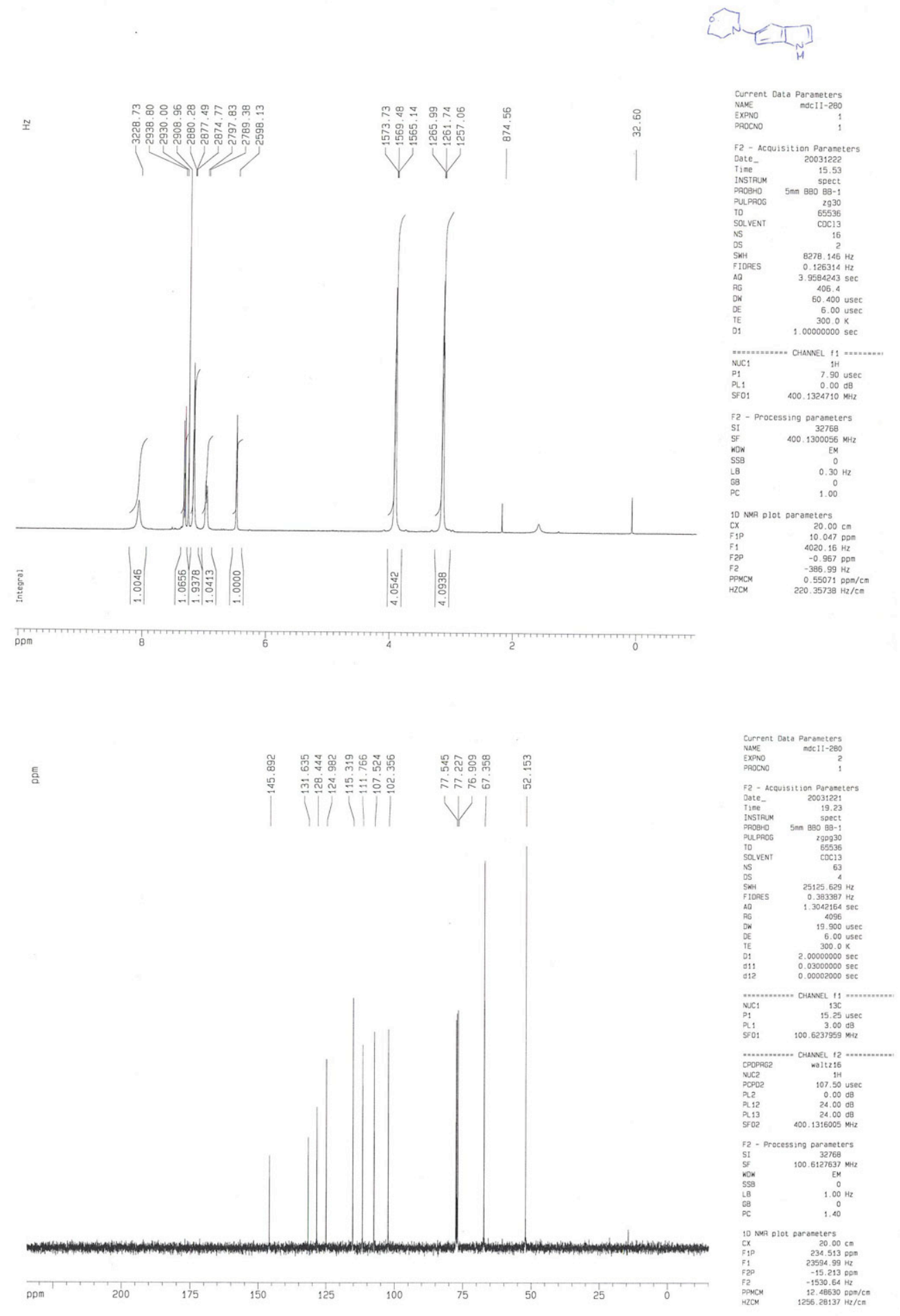


Dibutyl-(1H-indol-5-yl)-amine (Table 4, Entry 3). Following general procedure 2, a mixture of 5-bromoindole $(0.098 \mathrm{~g}, 0.50 \mathrm{mmol})$, di- $n$-butylamine $(0.077 \mathrm{~g}, 0.101 \mathrm{~mL}$, $0.60 \mathrm{mmol})$, lithium bis(trimethylsilyl)amide $(1.10 \mathrm{~mL}, 1.0 \mathrm{M}$ solution in THF, 1.10 $\mathrm{mmol}$ ), 1 (5.7 mg, $0.012 \mathrm{mmol}, 1.2 \mathrm{~mol} \%$ ), $\mathrm{Pd}_{2} \mathrm{dba}_{3}$ (4.6 mg, $0.005 \mathrm{mmol}, 0.5 \mathrm{~mol} \%$ ) and THF ( $1 \mathrm{~mL})$ was stirred at $65{ }^{\circ} \mathrm{C}$ for $24 \mathrm{~h}$. The crude reaction mixture was purified by flash column chromatography using 1:4 ethyl acetate:hexane $+2 \% \mathrm{Et}_{3} \mathrm{~N}$ to yield the title compound as a dark yellow oil $(0.065 \mathrm{~g}, 53 \%) .{ }^{1} \mathrm{H}$ NMR $\left(400 \mathrm{MHz} \mathrm{CDCl}_{3}\right): \delta 7.92$ (s, br, $1 \mathrm{H}), 7.26(\mathrm{~d}, J=8.7 \mathrm{~Hz}, 1 \mathrm{H}), 7.13(\mathrm{t}, J=2.7 \mathrm{~Hz}, 1 \mathrm{H}), 6.99(\mathrm{~d}, J=2.1 \mathrm{~Hz}, 1 \mathrm{H}), 6.84(\mathrm{dd}$, $J=8.7 \mathrm{~Hz}, 2.3 \mathrm{~Hz}, 1 \mathrm{H}), 6.44-6.43(\mathrm{~m}, 1 \mathrm{H}), 3.23(\mathrm{t}, J=7.5 \mathrm{~Hz}, 4 \mathrm{H}), 1.59-1.52(\mathrm{~m}, 4 \mathrm{H})$, 1.36 (sextet, $J=14.9 \mathrm{~Hz}, 7.4 \mathrm{~Hz}, 4 \mathrm{H}), 0.94(\mathrm{t}, J=7.3 \mathrm{~Hz}, 6 \mathrm{H}) .{ }^{13} \mathrm{C}$ NMR $(100 \mathrm{MHz}$ $\left.\mathrm{CDCl}_{3}\right): \delta 143.8,130.0,128.9,124.5,113.6,111.4,105.7,102.1,52.9,29.7,20.7,14.3$. IR (thin film cm $\mathrm{cm}^{-1}$ ) 3483, 3408, 2958, 2933, 2873, 1627, 1576, 1513, 1472, 1368, 1219, 1179, 1131, 904, 721. Anal. Calcd for $\mathrm{C}_{16} \mathrm{H}_{24} \mathrm{~N}_{2}$ : C, 78.64. H, 9.90.
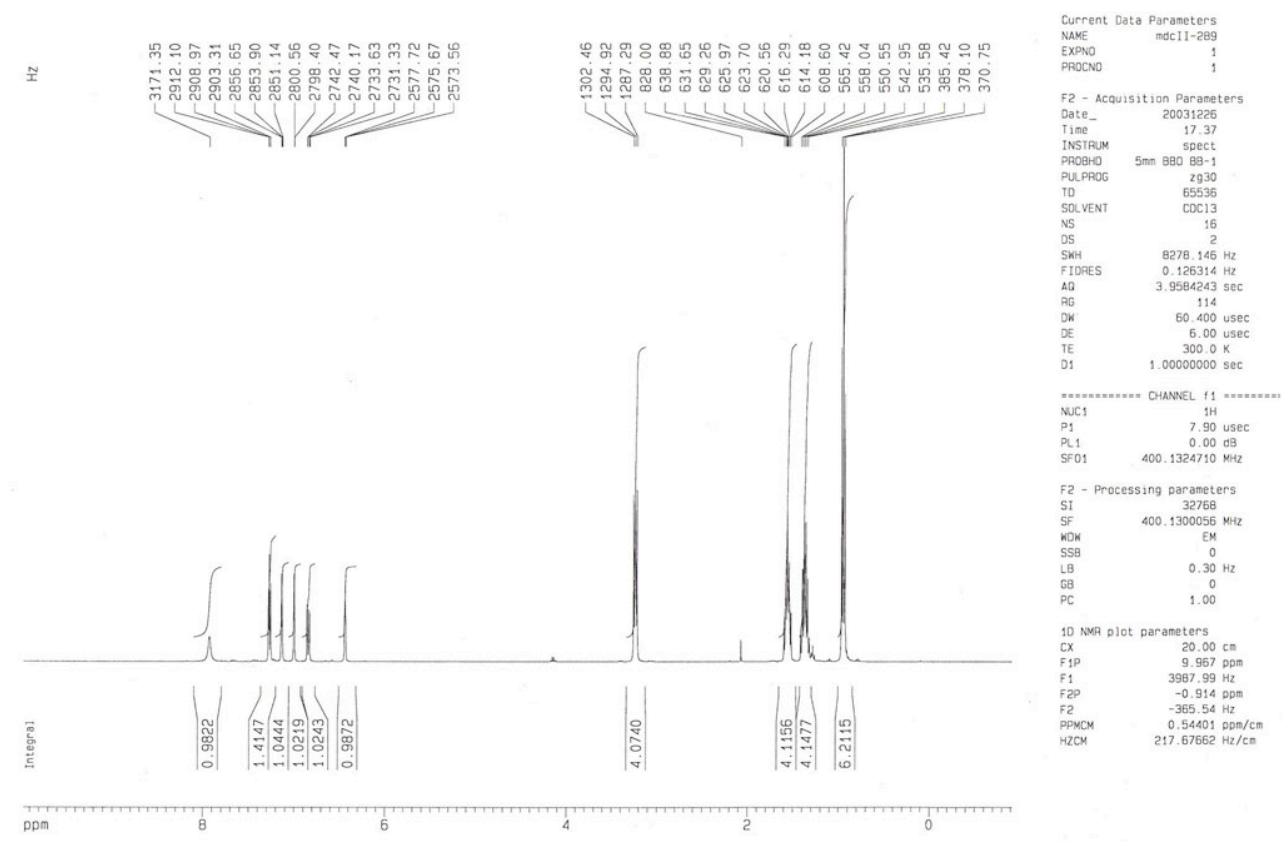


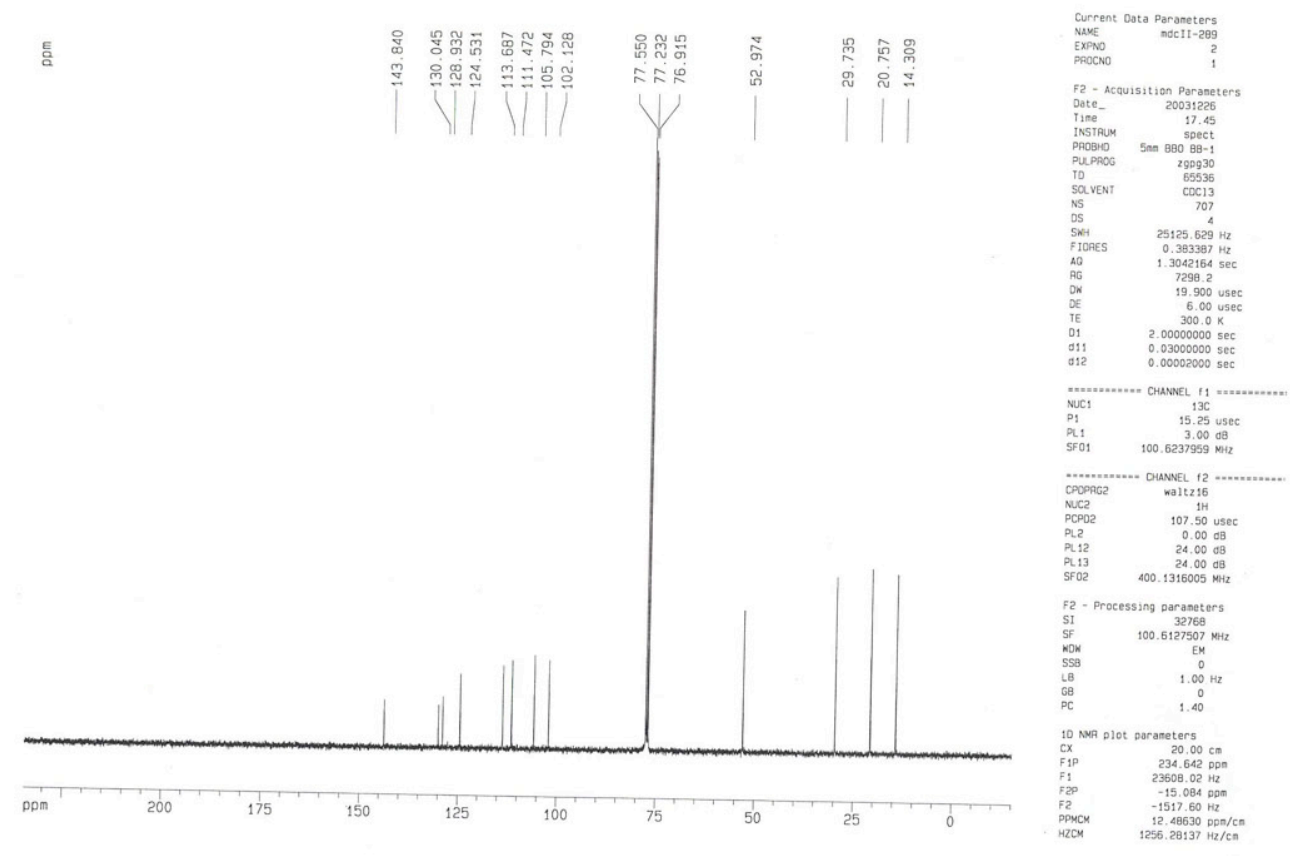

6-Piperidin-1-yl-1H-indole (Table 4, Entry 4). Following general procedure 2. a mixture of 6-chloroindole $(0.151 \mathrm{~g}, 1.00 \mathrm{mmol})$, piperidine $(0.102 \mathrm{~g}, 0.118 \mathrm{~mL}, 1.20$ mmol), lithium bis(trimethylsilyl)amide $(2.20 \mathrm{~mL}, 1.0 \mathrm{M}$ solution in THF, $2.20 \mathrm{mmol}), 1$ (11 mg, $0.024 \mathrm{mmol}, 2.4 \mathrm{~mol} \%), \mathrm{Pd}_{2} \mathrm{dba}_{3}(9.1 \mathrm{mg}, 0.01 \mathrm{mmol}, 1 \mathrm{~mol} \%$ ) and THF (1 mL) was stirred at $65{ }^{\circ} \mathrm{C}$ for $24 \mathrm{~h}$. The crude reaction mixture was purified by flash column chromatography using 3:7 ethyl acetate:hexane followed by trituration with diisopropyl ether yielded the title compound as a white solid $(0.125 \mathrm{~g}, 63 \%), \mathrm{mp} 153-154{ }^{\circ} \mathrm{C} .{ }^{1} \mathrm{H}$ NMR (400 MHz CDCl $\left.{ }_{3}\right): \delta 8.03(\mathrm{~s}, \mathrm{br}, 1 \mathrm{H}), 7.52(\mathrm{~d}, J=8.5 \mathrm{~Hz}, 1 \mathrm{H}), 7.10-7.08(\mathrm{~m}, 1 \mathrm{H})$, 6.94-6.92 (m, 2H), 6.47, (s, 1H), $3.14(\mathrm{t}, J=5.3 \mathrm{~Hz}, 4 \mathrm{H}), 1.81-1.76(\mathrm{~m}, 4 \mathrm{H}), 1.63-1.57$ $(\mathrm{m}, 2 \mathrm{H}) .{ }^{13} \mathrm{C}$ NMR $\left(100 \mathrm{MHz} \mathrm{CDCl}_{3}\right): \delta 149.4,136.9,122.9,122.0,120.9,113.9,102.4$, 98.8, 52.9, 26.4, 24.5. IR (thin film $\mathrm{cm}^{-1}$ ) 3161, 3130, 3118, 2935, 2860, 2811, 1598, 1576, 1497, 1482, 1447, 1256, 1026, 1171, 1129, 1094, 1059, 1027, 849.0, 771.8, 708.1. Anal. Calcd for $\mathrm{C}_{13} \mathrm{H}_{16} \mathrm{~N}_{2}$ : C, 77.96. $\mathrm{H}, 8.05$. 


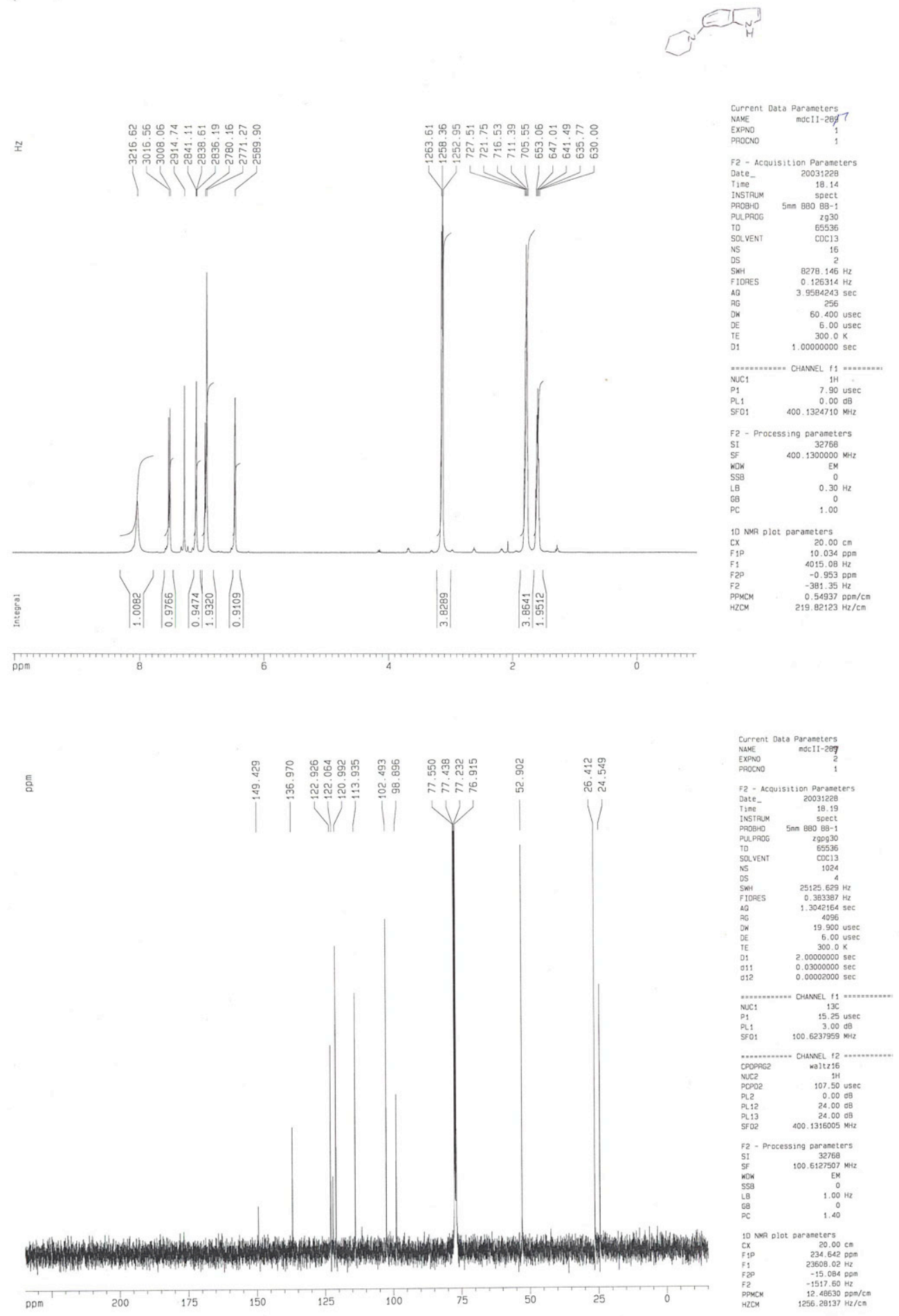

(1) Hooper, M. W.; Utsunomiya, M.; Hartwig, J. F. J. Org. Chem. 2003, 68, 2861-2873.

(2) D’Amico, J. J.; Webster, S. T.; Campbell, R. H.; Twine, C. E. J. Org. Chem. 1965, 30, 3618-3625. 